\title{
Genome and secretome analysis of the hemibiotrophic fungal pathogen, Moniliophthora roreri, which causes frosty pod rot disease of cacao: mechanisms of the biotrophic and necrotrophic phases
}

Lyndel W Meinhardt ${ }^{*}$, Gustavo Gilson Lacerda Costa ${ }^{2}$, Daniela PT Thomazella ${ }^{3}$, Paulo José PL Teixeira ${ }^{3}$, Marcelo Falsarella Carazzolle ${ }^{2}$, Stephan C Schuster ${ }^{4}$, John E Carlson ${ }^{5}$, Mark J Guiltinan ${ }^{6}$, Piotr Mieczkowski ${ }^{7}$, Andrew Farmer ${ }^{8}$, Thiruvarangan Ramaraj ${ }^{8}$, Jayne Crozier $^{9}$, Robert E Davis ${ }^{10}$, Jonathan Shao ${ }^{10}$, Rachel L Melnick , Gonçalo AG Pereira ${ }^{3}$ and Bryan A Bailey ${ }^{1}$

\begin{abstract}
Background: The basidiomycete Moniliophthora roreri is the causal agent of Frosty pod rot (FPR) disease of cacao (Theobroma cacao), the source of chocolate, and FPR is one of the most destructive diseases of this important perennial crop in the Americas. This hemibiotroph infects only cacao pods and has an extended biotrophic phase lasting up to sixty days, culminating in plant necrosis and sporulation of the fungus without the formation of a basidiocarp.
\end{abstract}

Results: We sequenced and assembled $52.3 \mathrm{Mb}$ into 3,298 contigs that represent the $\mathrm{M}$. roreri genome. Of the 17,920 predicted open reading frames (OFRs), 13,760 were validated by RNA-Seq. Using read count data from RNA sequencing of cacao pods at 30 and 60 days post infection, differential gene expression was estimated for the biotrophic and necrotrophic phases of this plant-pathogen interaction. The sequencing data were used to develop a genome based secretome for the infected pods. Of the 1,535 genes encoding putative secreted proteins, 1,355 were expressed in the biotrophic and necrotrophic phases. Analysis of the data revealed secretome gene expression that correlated with infection and intercellular growth in the biotrophic phase and invasive growth and plant cellular death in the necrotrophic phase.

Conclusions: Genome sequencing and RNA-Seq was used to determine and validate the Moniliophthora roreri genome and secretome. High sequence identity between Moniliophthora roreri genes and Moniliophthora perniciosa genes supports the taxonomic relationship with Moniliophthora perniciosa and the relatedness of this fungus to other basidiomycetes. Analysis of RNA-Seq data from infected plant tissues revealed differentially expressed genes in the biotrophic and necrotrophic phases. The secreted protein genes that were upregulated in the biotrophic phase are primarily associated with breakdown of the intercellular matrix and modification of the fungal mycelia, possibly to mask the fungus from plant defenses. Based on the transcriptome data, the upregulated secreted proteins in the necrotrophic phase are hypothesized to be actively attacking the plant cell walls and plant cellular components resulting in necrosis. These genes are being used to develop a new understanding of how this disease interaction progresses and to identify potential targets to reduce the impact of this devastating disease.

\footnotetext{
* Correspondence: lyndel.meinhardt@ars.usda.gov

${ }^{1}$ Sustainable Perennial Crops Lab, USDA/ARS, Bldg 001 Rm 223 Beltsville

Agricultural Research Center-West, Beltsville, MD 20705, USA

Full list of author information is available at the end of the article
} 


\section{Background}

Fungal plant pathogens can be classified as biotrophic, necrotrophic or hemibiotrophic pathogens based on how they interact with their host. Biotrophic pathogens cause only minor responses from the plant, particularly at initial stages of the disease. These biotrophic pathogens appear to evade plant defenses with stealthy methods [1]. Fungal biotrophs are often obligate pathogens, typically having narrow host ranges, possessing haustoria and secreting limited amounts of lytic enzymes [2]. On the other hand, infection by necrotrophic pathogens causes rapid cell death in hosts and elicit major molecular responses from the plant. Necrotrophs appear to utilize brute force and overwhelm the plant defenses. Necrotrophs are typically non-obligate pathogens, have wide host ranges and secrete copious amounts of lytic enzymes and toxins [2]. Hemibiotrophs initiate infection with a period of biotrophy, followed by a necrotrophic phase, and they possess properties of both groups. However, most of our understanding of how hemibiotrophs interact with their hosts is derived from these two extremes.

Both biotrophic and necrotrophic fungi share common elements but these may have different purposes when causing disease. During the host-interaction, the pathogens synthesize and secrete various peptides/proteins that block host responses (biotrophs) or kill the host cells (necrotrophs). Among biotrophs, the rust fungus of flax, Melampsora lini, excretes cysteine-rich avirulence elicitor proteins from the haustoria [3] and the bean rust fungus Uromyces fabae shows highly coordinated stage specific regulation of its secreted proteins [4]. The necrotrophic fungus Fusarium graminearum has 109 secreted cell wall degrading genes in its genome [5], while Alternaria species secrete non-host and host specific toxins that disrupt photosynthesis and kill plant cells [6]. Therefore, a detailed understanding of specific peptides/proteins secreted during the host-pathogen interaction is vital to elucidate the biotrophic and necrotrophic mechanisms.

Moniliophthora roreri (Cif.) H.C. Evans, Stalpers, Samson \& Benny [7] causes Frosty Pod Rot (FPR), a devastating pod disease of Theobroma cacao L. (cacao), the source of cocoa powder and cocoa butter. Phylogenetically, M. roreri is related to another fungal pathogen, Moniliophthora perniciosa (Stahel) Aime and Phillips-Mora [8], which causes Witches' Broom Disease (WBD), a disease that infects all cacao meristematic tissues including flowers, shoots, and pods [8]. Together, these pathogens cause two of the most economically important diseases of Theobroma cacao in the Western Hemisphere $[9,10]$. While both of these fungal species are pathogenic on the plant genera Theobroma and Herrania, M. roreri is not known to have any other hosts, whereas $M$. perniciosa has distinct biotypes that infect different host species [11]. Historically, these Moniliophthora pathogens have spread independently to cacao producing areas across the Western Hemisphere and they have typically resulted in production losses of $75 \%$ or higher in nearly all the cacao growing regions in the Americas $[10,12]$.

Moniliophthora roreri and M. perniciosa are both hemibiotrophic pathogens, but have distinctive lifestyles and pathogenicity strategies. Unlike most other hemibiotrophic fungi, both Moniliophthora species have protracted biotrophic stages or phases that last three to six weeks. They also have distinctly different mycelial morphologies present at the beginning and the end of the disease process [10,13]. In both Moniliophthora diseases, the infected plant tissues are asymptomatic for 14 to 21 days. After that period of time, these tissues typically begin to show some form of altered growth or swelling that continues for the remainder of the biotrophic phase, culminating with the necrosis of the host tissues, which marks the beginning of the necrotrophic phase. In other hemibiotrophic fungi such as Cladosporium fulvum, Mycosphaerella graminicola, Pyrenopeziza brassicae and Septoria tritici, the biotrophic phase is asymptomatic with undifferentiated mycelia and lasts no more than two weeks [14].

As with hemibiotrophic Colletotrichum species, both $M$. roreri and $M$. perniciosa undergo distinct metabolic changes as they transition from the biotrophic phase to the necrotrophic phase of growth [15-19]. These metabolic changes suggest significant shifts in gene expression and in enzymatic processes.

In this study we present the genome of $M$. roreri and compare it to the genome of the closely related cacao pathogen, M. perniciosa. Transcriptional analysis of the genome will focus on genes with putative signal peptides from the $M$. roreri genome and compare them with expressed genes, identified through RNA sequencing of infected pods, to discover potential secreted proteins expressed during the disease process. Genes expressed in the early and late stages of FPR on pods were used to identify secreted genes that are potentially important during the biotrophic or necrotrophic phase of the disease cycle. The results presented here are the first analyses of genes encoding secreted proteins derived from the $M$. roreri genome. These new insights into the $M$. roreri genome, transcriptome and differential gene regulation provide a better understanding of the plant-pathogen interactions that occur during FPR.

\section{Results}

\section{Genome structure}

Moniliophthora roreri has a genome size of $52.3 \mathrm{Mbp}$, which is 7.7 Mbp larger than the 44.6 Mbp found in the M. perniciosa genome (Table 1). Despite the size difference, $M$. roreri had only 912 additional coding sequences (CDS) than M. perniciosa. 17,920 coding sequences were detected in M. roreri. The average GC\% for the $M$. roreri 
Table 1 Genome Comparisons of $M$. roreri and $M$. perniciosa

\begin{tabular}{|c|c|c|c|c|c|c|c|c|c|c|c|c|c|}
\hline & $\begin{array}{l}\text { Genome } \\
\text { size (bp) }\end{array}$ & $\begin{array}{l}\text { Average } \\
(G+C) \%\end{array}$ & $\begin{array}{c}\text { Total } \\
\text { number } \\
\text { contigs }\end{array}$ & $\begin{array}{l}\text { N50 } \\
\text { (bp) }\end{array}$ & $\begin{array}{c}\text { Max } \\
\text { contig } \\
\text { size (bp) }\end{array}$ & $\begin{array}{c}\text { Min } \\
\text { contig } \\
\text { size (bp) }\end{array}$ & $\begin{array}{l}\text { Median } \\
\text { contig } \\
\text { size }\end{array}$ & $\begin{array}{l}\text { Total } \\
\text { tRNA }\end{array}$ & $\begin{array}{c}\text { Avg } \\
\text { gene } \\
\text { Density }\end{array}$ & $\begin{array}{l}\text { Total } \\
\text { CDS }\end{array}$ & $\begin{array}{l}\text { Avg } \\
(G+C) \\
\text { CDS\% }\end{array}$ & $\begin{array}{l}\text { Maximum } \\
\text { CDS size } \\
\text { (bp) }\end{array}$ & $\begin{array}{l}\text { Median } \\
\text { CDS size } \\
\text { (bp) }\end{array}$ \\
\hline & 375 & $46.88 \%$ & 3,298 & 48,134 & 571,142 & 367 & 5,455 & $670^{*}$ & $0.42185 \#$ & 0 & $9.55 \%$ & 15 & 1,023 \\
\hline & 661,472 & $31 \%$ & 3,087 & 096 & 76,325 & 500 & 3,300 & 550 & $0.51058 \#$ & 17,008 & $9.83 \%$ & 15,048 & 1,095 \\
\hline
\end{tabular}

perniciosa

*using tRNAscan default parameters yielded 331 contigs that have tRNA for a total of 670 tRNA's.

\#CDS bases/total genome bases.

genome $(46.88 \%)$ is lower than for the $M$. perniciosa genome (47.81\%); however, the average $\mathrm{G}+\mathrm{C}$ for the $M$. roreri CDS is nearly identical to the value for $M$. perniciosa. Gene density for $M$. roreri was also found to be lower than for $M$. perniciosa.

An analysis of the genomes of these pathogens has revealed that retro-transposons (LTRs) contribute to about $6.6 \%(3.46 \mathrm{Mbp})$ of the $M$. roreri genome compared to about $0.74 \%(0.332 \mathrm{Mbp})$ in the $M$. perniciosa genome. In $M$. perniciosa, transposable elements were reported to be active elements that may contribute to genetic variability of this pathogen [20]. Each genome was scanned for repetitive sequences and low complexity DNA using the Repeat Modeler and RepeatMasker programs. $M$. roreri had 7,060,129 bases associated with repeats and repetitive elements while $M$. perniciosa had 1,737,865 bases associated with repeats and repetitive elements (Additional file 1).

\section{Synteny}

Using a bi-directional blast with an E-value of E-04 as the cut-off value for two proteins being considered a match, a whole genome comparison of the predicted proteins between the $M$. roreri and $M$. perniciosa genomes was performed. This analysis revealed that 16,713 protein encoding genes (93\%) from $M$. roreri have sequence similarity to $M$. perniciosa protein encoding genes and 15,674 protein encoding genes (92\%) from $M$. perniciosa have sequence similarity to $M$. roreri protein encoding genes. At lower E-values, E-25 and E 0.0, the $M$. roreri genome open reading frames (ORFs) are $87 \%$ and $40 \%$ similar to the $M$. perniciosa genome ORFs, respectively. In $M$. roreri there are 8,851 predicted genes or $49 \%$ that have no predicted function and are listed as hypothetical genes. Synteny between $M$. roreri and $M$. perniciosa was analyzed with the program MUMmer using the NUCmer setting that compares the contigs from both genomes at the nucleotide level. In this analysis, $M$. roreri contigs were queried using $M$. perniciosa contigs as the reference sequence. Contigs with high sequence identity resulted in a straight line graph, while translocations and inversions result in either a parallel shift in the line (up or down) or a line at a negative angle, respectively. Though both genomes are closely related at the nucleotide level, there are regions where inversions and translocations have potentially occurred. This analysis confirms that these two genomes are very similar and most probably homologous, while it also shows that some regions in both genomes are unique. Due to the poor resolution of the MUMmer plot when all genome contigs were analyzed, we compared long intact regions of the genomes. Two hundred and fifty contigs from $M$. roreri and 233 contigs from $M$. perniciosa were compared that were at least $50 \mathrm{~kb}$ in length. Contigs with no corresponding sequence identity were eliminated, so that only contigs of high sequence identity between the two genomes were compared (Figure 1). The results yielded a final comparison of 222 contigs from $M$. roreri and 207 contigs from M. perniciosa and showed highly similar sequences with slight shifts off the diagonal line, which indicate translocations in the contigs (Figure 1 insert that shows an expanded region of the main figure).

\section{Comparisons to other basidiomycete fungi}

Bidirectional blast analysis was conducted with $M$. roreri, M. perniciosa, Laccaria bicolor, Coprinopsis cinerea (Coprinus cinereus), and Ustilago maydis. These other genomes were selected because all are basidiomycetes but exhibit differing environmental adaptations representing a mushroom producing ectomycorrhizae a mushroom producing saprophyte and a pathogenic smut fungus, respectively. Figure 2 presents the Venn-diagram of the analysis, and the tax plot is shown in Table 2. Each of the five genomes is represented by an oval, and the numbers indicate how many genes are included within that intersect, at an E-value of E-04. Using this analysis, genes can be identified that are exclusive to a particular genome or to a particular group, which enables identification of putative similarities such as pathogenicity genes, and genus specific genes. The number of predicted genes particular to a single genome is: 1,133 for (A) $M$. roreri, 1,202 for (B) $M$. perniciosa, 5,568 for (C) L. bicolor, 2,539 for (D) C. cinerea and 1,324 for (E) $U$. maydis. Only seven of the $1,133 \mathrm{M}$. roreri genes were detected by RNA-Seq analysis (described below) and only 16 of the 1,133 $M$. roreri genes have putative functions (Table 3). Based on the annotation, several of these genes appear to have a role in genome integrity and function (a RNA polymerase Rpb1 C-terminal repeat domain-containing protein; a putative RecQ helicase; a P-loop containing nucleoside triphosphate hydrolase protein) while another set appears to be linked to retro 


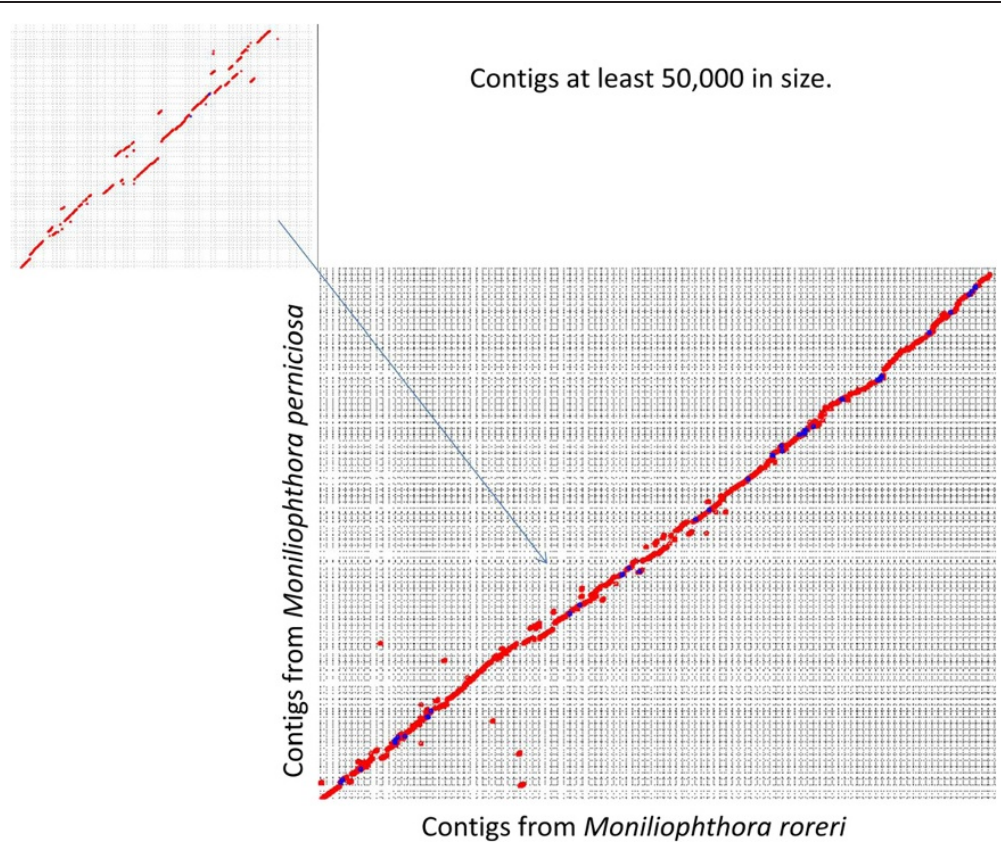

Figure 1 MUMmer alignment dot plot of $\boldsymbol{M}$. roreri and $\boldsymbol{M}$. perniciosa contigs using only contigs $\mathbf{5 0} \mathbf{k b}$ or larger. The line graph represents the MUMmer results for the nucleotide comparison of $M$. roreri contigs to $M$. perniciosa contigs with a size cutoff of $50 \mathrm{~kb}$. Only contigs larger than $50 \mathrm{~kb}$ were compared and contigs with no corresponding homology were eliminated from this particular analysis. Red circles represent positive strand alignments while blue circles represent negative strand alignments. The insert represent an enlargement of the MUMmer graph at that location. The $50 \mathrm{~kb}$ contigs utilized in this analysis for $\mathrm{M}$. roreri account for $23,142,326 \mathrm{bp}$ or $44 \%$ of the total $52,334,081$ bp genome, where as for M. perniciosa $21,535,677$ bp were, used which represents $48 \%$ of the $44,661,472$ bp genome.

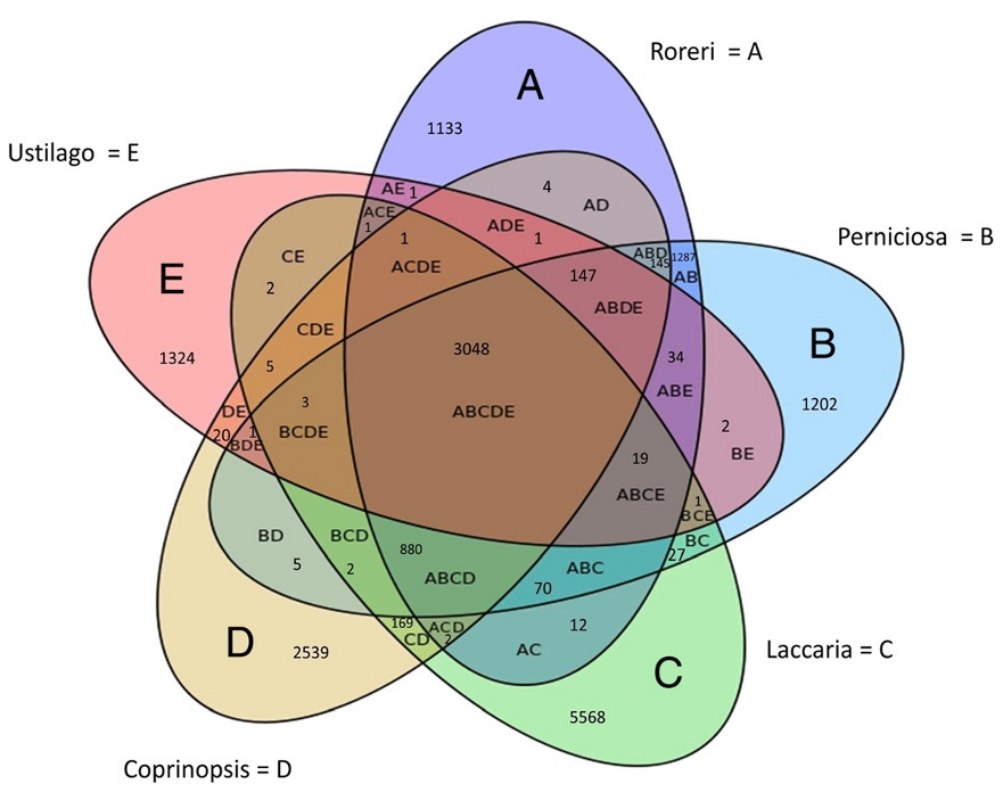

Figure 2 Bi-directional Venn diagram. Bi-directional blast results are present in a Venn diagram. The code used for this diagram is: $\mathbf{A}$ oval $=M$. roreri genes; the $\mathbf{B}$ oval $=M$. perniciosa genes; $\mathbf{C}$ oval $=L$. bicolor genes; $\mathbf{D}$ oval $=\mathbf{C}$. cinerea genes and $\mathbf{E}$ oval $=U$. maydis genes. Intersects are labeled with the corresponding letters and a number which represents the number of specific genes in that particular intersect. An E-value E-04 was used as the homology cut off. 
Table 2 Tax plot results of the bi-directional blast analysis

\begin{tabular}{|c|c|c|c|c|}
\hline \multicolumn{4}{|c|}{ Bidirectional blast results } & $\begin{array}{l}\text { Venn } \\
\text { intersection \# }\end{array}$ \\
\hline A-1133 & & & & 1133 \\
\hline AB-2982 & BA-2508 & & & 1287 \\
\hline$A C-34$ & CA-86 & & & 12 \\
\hline$A D-13$ & DA-26 & & & 4 \\
\hline$\overline{A E}-2$ & EA-17 & & & 1 \\
\hline ABC-866 & BAC-526 & CAB-479 & & 70 \\
\hline ABD-540 & BAD-486 & DAB-395 & & 145 \\
\hline ABE-136 & BAE-125 & EAB-100 & & 34 \\
\hline ACD-25 & CAD-101 & DAC-57 & & 2 \\
\hline ACE-0 & CAE-2 & EAC-5 & & 1 \\
\hline$\overline{A D E}-0$ & DAE-2 & EAD-8 & & 1 \\
\hline$A B C D-3650$ & BACD-3819 & CABD-3739 & DABC-2957 & 880 \\
\hline ABCE-192 & BACE-144 & CABE-89 & EABC-123 & 19 \\
\hline ABDE-348 & BADE-355 & DABE-265 & EABD-254 & 147 \\
\hline ACDE-0 & CADE-8 & DACE-6 & EACD-8 & 1 \\
\hline ABCDE-7998 & BACDE-7711 & CABDE-6535 & DABCE-6126 & 3048 \\
\hline B-1202 & & & & 1202 \\
\hline $\mathrm{BC}-61$ & CB-249 & & & 27 \\
\hline $\mathrm{BD}-33$ & DB-71 & & & 5 \\
\hline $\mathrm{BE}-2$ & EB-22 & & & 2 \\
\hline BCD-38 & CBD-366 & DBC-182 & & 2 \\
\hline BCE-0 & CBE-5 & EBC-9 & & 1 \\
\hline BDE-1 & DBE-2 & EBD-7 & & 1 \\
\hline BCDE-5 & CBDE-18 & DBCE-9 & EBCD-22 & 3 \\
\hline$C-5568$ & & & & 5568 \\
\hline CD-904 & DC-659 & & & 169 \\
\hline CE-22 & EC-40 & & & 2 \\
\hline CDE-44 & DCE-31 & ECD-37 & & 5 \\
\hline D-2539 & & & & 2539 \\
\hline $\mathrm{DE}-29$ & ED-53 & & & 20 \\
\hline E-1324 & & & & 1324 \\
\hline
\end{tabular}

elements (a Gag protein, retrovirus-related Pol polyprotein from transposon TNT 1-94 and a reverse transcriptase protein). The remaining genes have similarity to a mix of toxins (volvatoxin A2 precursor, a dipterans toxic crystal protein); heme binding (a Hemopexin domaincontaining protein); cell adhesion (a calcium-binding tyrosine phosphorylation-regulated protein); pectin degradation (a probable pectin lyase precursor); possible oxidoreductases (two FAD NAD-binding domain-containing proteins); a putative $\mathrm{CNVH}$-domain-containing protein and two capsule polysaccharide biosynthesis proteins. The ABCDE intersection contains 3,048 genes (data not shown), which are common to all of these basidiomycetes, while there are 34 genes associated with $\mathrm{ABE}$ and 70 with $\mathrm{ABC}$. The Moniliophthora intersect (AB) has 1,287 genes, of which
Table $3 \mathbf{M}$. roreri intersect

\begin{tabular}{ll}
\hline A intersect & \\
Gene Id & Gene annotation \\
\hline evm.model. & $\begin{array}{l}\text { Calcium-binding tyrosine phosphorylation- } \\
\text { regulated }\end{array}$ \\
\hline sctg_0272_0002.2 & Capsule polysaccharide biosynthesis \\
evm.model. & \\
\hline sctg_0180_0002.8 & Capsule polysaccharide biosynthesis \\
evm.model. & \\
\hline sctg_0180_0002.6 & CNVH-domain-containing protein \\
sctg_0121_0002.16 & \\
\hline evm.model. & Dipterans toxic crystal protein \\
sctg_0631_0001.1 & \\
\hline evm.model. & FAD NAD-binding domain-containing protein \\
sctg_0013_0001.105 & \\
\hline evm.model. & FAD NAD-binding domain-containing protein \\
sctg_0013_0001.104 & \\
\hline evm.model. & Gag protein \\
sctg_1050_0001.1 & \\
\hline evm.model. & Hemopexin domain-containing protein \\
sctg_0048_0006.5 & \\
\hline evm.model. & P-loop containing nucleoside triphosphate \\
sctg_0344_0002.10 & hydrolase protein \\
\hline evm.model. & Probable pectin lyase precursor \\
sctg_0066_0001.15 & \\
\hline evm.model. & Putative RecQ helicase \\
sctg_0665_0003.1 & \\
\hline evm.model. & Retrovirus-related pol polyprotein from \\
sctg_0517_0002.1 & transposon tnt 1-94 \\
\hline evm.model. & Reverse transcriptase \\
sctg_1099_0001.3 & \\
\hline evm.model. & RNA polymerase Rpb1 C-terminal repeat \\
sctg_0028_0009.5 & domain-containing protein \\
\hline evm.model. & Volvatoxin A2 precursor \\
\hline
\end{tabular}

only 106 or $8 \%$ have a putative function (Table 4). Among the $\mathrm{AB}$ genes there are five antibiotic biosynthesis monooxygenases; five feruloyl esterases involved in hemicellulose degradation; four cellulose binding proteins; four cell wall glycosyl hydrolases, involved in cell wall sugar degradation; four chitin binding proteins; four het domain proteins associated with fungal vegetative incompatibility and mycelial cell death; three pectate lyases involved in pectin degradation; three family 12 carbohydrate esterases, a family that includes pectin acetylesterases, rhamnogalacturonan acetylesterases and acetyl xylan esterases; three biotrophy-associated secreted proteins that are putative effectors and 2 amidohydrolases, enzymes that act on amide bonds. Most of these $A B$ intersect genes were constitutively expressed, but RNA-Seq data also showed differential gene expression for 14 genes, which are indicated in Table 4 (Additional file 1). In the necrotrophic phase the following genes were upregulated: an antibiotic biosynthesis monooxygenase, two biotrophy-associated secreted proteins, a cellulose binding protein, a FAD binding domain 
Table 4 Moniliophthora hemibiotrophic intersect AB intersect moniliophthora

\begin{tabular}{|c|c|}
\hline Gene Id & Gene annotation \\
\hline evm.model.sctg_0025_0003.30 & 3-carboxymuconate cyclase \\
\hline evm.model.sctg_0188_0002.6 & Acetamidase formamidase \\
\hline $\begin{array}{l}\text { evm.model. } \\
\text { sctg_0009_0002.120 }\end{array}$ & Alpha beta hydrolase fold protein \\
\hline evm.model.sctg_0055_0002.11 & Amidohydrolase \\
\hline evm.model.sctg_0260_0001.15 & Amidohydrolase \\
\hline evm.model.sctg_0053_0001.15 & Antibiotic biosynthesis monooxygenase \\
\hline evm.model.sctg_0072_0001.2 & Antibiotic biosynthesis monooxygenase \\
\hline evm.model.sctg_0210_0002.9 $9^{\mathrm{N}}$ & $\begin{array}{l}\text { Antibiotic biosynthesis } \\
\text { monooxygenase }^{N}\end{array}$ \\
\hline evm.model.sctg_0108_0002.35 & $\begin{array}{l}\text { Antibiotic biosynthesis monooxygenase } \\
\text { domain protein }\end{array}$ \\
\hline evm.model.sctg_0150_0003.5 & Arabinofuranosidase \\
\hline evm.model.sctg_0211_0001.12 & Aryl sulfotransferase \\
\hline $\begin{array}{l}\text { evm.model. } \\
\text { sctg_0005_0005.16 }\end{array}$ & Biotrophy-associated secreted protein $2^{N}$ \\
\hline $\begin{array}{l}\text { evm.model. } \\
\text { sctg_0066_0001.46 }\end{array}$ & Biotrophy-associated secreted protein $2^{N}$ \\
\hline evm.model.sctg_0104_0004.11 & Biotrophy-associated secreted protein 2 \\
\hline evm.model.sctg_0099_0003.12 & $\begin{array}{l}\text { C6 zinc finger domain-containing } \\
\text { protein }\end{array}$ \\
\hline evm.model.sctg_0024_0001.46 & Carbohydrate esterase family 12 protein \\
\hline evm.model.sctg_0025_0003.31 & Carbohydrate esterase family 12 protein \\
\hline evm.model.sctg_0086_0003.12 & Carbohydrate esterase family 12 protein \\
\hline evm.model.sctg_0066_0001.40 & $\begin{array}{l}\text { Carboxyphosphonoenolpyruvate } \\
\text { phosphonomutase-like protein }\end{array}$ \\
\hline evm.model.sctg_0063_0003.8 & Cell wall glycosyl hydrolase \\
\hline evm.model.sctg_0155_0002.9 & Cell wall glycosyl hydrolase \\
\hline evm.model.sctg_0155_0004.12 & Cell wall glycosyl hydrolase \\
\hline $\begin{array}{l}\text { evm.model. } \\
\text { sctg_0155_0004.13 }\end{array}$ & Cell wall glycosyl hydrolase ${ }^{B}$ \\
\hline evm.model.sctg_0245_0001.21 & Cellulose-binding family ii \\
\hline $\begin{array}{l}\text { evm.model. } \\
\text { sctg_0176_0001.14 }\end{array}$ & Cellulose-binding protein $^{N}$ \\
\hline evm.model.sctg_0243_0004.9 & Cellulose-binding protein \\
\hline evm.model.sctg_0065_0001.23 & Chitin binding \\
\hline evm.model.sctg_0068_0003.6 & Chitin binding \\
\hline evm.model.sctg_0086_0003.11 & Chitin binding \\
\hline evm.model.sctg_0086_0003.19 & Chitin binding \\
\hline evm.model.sctg_0149_0001.3 & Cysteine-rich secreted protein \\
\hline evm.model.sctg_0011_0002.81 & duf1446 domain containing protein \\
\hline evm.model.sctg_0073_0003.23 & duf1446 domain containing protein \\
\hline evm.model.sctg_0091_0003.16 & duf567 domain protein \\
\hline evm.model.sctg_0008_0001.9 & duf718 domain protein \\
\hline evm.model.sctg_0119_0001.2 & duf985 domain protein \\
\hline evm.model.sctg_0121_0002.8 & endo- -beta-xylanase precursor \\
\hline evm.model.sctg_0132_0002.1 & Epoxidase subunit a \\
\hline evm.model.sctg_0072_0002.6 & Erylysin b \\
\hline
\end{tabular}

Table 4 Moniliophthora hemibiotrophic intersect (Continued)

evm.model.sctg_0042_0004.3 Excitatory amino acid transporter

evm.model.sctg_0050_0004.25 Exonuclease

evm.model.sctg_0022_0002.37 Extracellular chitosanase

evm.model. FAD binding domain protein $^{\mathrm{N}}$

sctg_0054_0001.12

evm.model.sctg_0133_0001.4 Feruloyl

evm.model.sctg_0015_0003.16 Fructose-bisphosphate aldolase

evm.model.sctg_0101_0001.1 Fusicoccadiene synthase

evm.model.sctg_0206_0002.8 General substrate transporter-like protein

evm.model.sctg_0214_0001.8 Glucokinase regulator family

evm.model.

sctg_0011_0002.91 ${ }^{\mathrm{B}}$

Glycoside hydrolase family 16 protein $^{B}$

evm.model.sctg_0011_0002.92 Glycoside hydrolase family 16 protein

evm.model.sctg_0091_0003.6 Glycoside hydrolase family 29 protein

evm.model.sctg_0120_0002.15 Glycoside hydrolase family 29 protein

evm.model.sctg_0195_0003.1 Glycoside hydrolase family 78 protein

evm.model.sctg_0063_0003.36 Glycosyl family

evm.model.sctg_0002_0008.34 Glycosyl hydrolase family 32

evm.model.sctg_0120_0001.8 Het domain containing protein

evm.model.sctg_0018_0003.8 Het domain protein

evm.model.sctg_0068_0003.29 Het domain protein

evm.model.sctg_0175_0002.5 Het domain protein

evm.model.sctg_0014_0004.20 Hydantoinase

evm.model.sctg_0008_0001.24 Hydroxycinnamoyl shikimate quinate hydroxycinnamoyltransferase

evm.model.sctg_0091_0003.1 ${ }^{\mathrm{N}}$ Integral membrane protein $^{\mathrm{N}}$

evm.model.sctg_0092_0002.20 Integral membrane protein

evm.model.sctg_0092_0002.22 Integral membrane protein

evm.model.sctg_0097_0001.11 Integral membrane protein

evm.model.sctg_0002_0010.51 Isochorismatase hydrolase

evm.model.sctg_0231_0001.20 Isoflavone reductase family protein

evm.model.sctg_0015_0001.8 Killer kp4 toxin

evm.model.sctg_0088_0001.8 ${ }^{\mathrm{N}}$ Lactam utilization protein $^{\mathrm{N}}$

evm.model.sctg_0023_0001.50 Lea domain protein

evm.model.sctg_0178_0001.5 ${ }^{\mathrm{N}}$ Lea domain-containing protein ${ }^{\mathrm{N}}$

evm.model.sctg_0005_0005.46 Lipoprotein

evm.model.sctg_0049_0006.14 l-lysine -2,3-aminomutase

evm.model.sctg_0002_0010.48 Major facilitator superfamily transporter

evm.model.sctg_0240_0001.1 Major royal jelly protein

evm.model.sctg_0023_0002.33 mannitol-1-phosphate 5-dehydrogenase

evm.model.sctg_0158_0002.2 Metal dependent phosphohydrolase

evm.model.

sctg_0081_0002.17

NAD-binding phosphogluconate dehydrogenase-like protein ${ }^{B}$

evm.model.sctg_0110_0001.5 NAD-binding phosphogluconate dehydrogenase-like protein

evm.model.sctg_0062_0002.32 nmra-like protein

evm.model.sctg_0026_0001.19 Pectate lyase

evm.model.sctg_0214_0001.16 Pectate lyase 
Table 4 Moniliophthora hemibiotrophic intersect (Continued)

\begin{tabular}{|c|c|}
\hline evm.model.sctg_0049_0006.8 & Phosphoglycerate mutase family \\
\hline evm.model.sctg_0049_0006.9 & Phosphoglycerate mutase family \\
\hline evm.model.sctg_0194_0001.15 & Plasmid $\mathrm{p} 4 \mathrm{~b}$ orf-3 family protein \\
\hline evm.model.sctg_0094_0005.7 & $\begin{array}{l}\text { P-loop containing nucleoside } \\
\text { triphosphate hydrolase protein }\end{array}$ \\
\hline evm.model.sctg_0014_0004.25 & Poxa3b laccase small subunit \\
\hline evm.model.sctg_0162_0004.8 & Proline racemase \\
\hline evm.model.sctg_0018_0002.9 & Proline-specific peptidase \\
\hline evm.model.sctg_0089_0002.36 & Protein tprxl \\
\hline evm.model.sctg_0122_0004.1 & Proteophosphoglycan ppg4 \\
\hline evm.model.sctg_0159_0004.4 & Purine nucleoside \\
\hline evm.model.sctg_0022_0002.64 & Putative zinc metallopeptidase protein \\
\hline evm.model.sctg_0100_0003.5 & Related to tol protein \\
\hline evm.model.sctg_0020_0001.61 & Serine threonine sps1 \\
\hline evm.model.sctg_0217_0001.20 & Surface cell-adhesion protein \\
\hline evm.model.sctg_0105_0006.2 $2^{\mathrm{N}}$ & Thaumatin-like protein $^{N}$ \\
\hline evm.model.sctg_0100_0003.7 & Tol-like protein \\
\hline evm.model.sctg_0098_0001.12 & Transcription regulator \\
\hline $\begin{array}{l}\text { evm.model. } \\
\text { sctg_0093_0001.28 }\end{array}$ & Transferase family protein ${ }^{N}$ \\
\hline evm.model.sctg_0016_0005.17 & Transposon en spm sub-class \\
\hline evm.model.sctg_0188_0001.3 & $\begin{array}{l}\text { Twin-arginine translocation } \\
\text { pathway signal }\end{array}$ \\
\hline evm.model.sctg_0041_0004.5 & Urea hydro-lyase cyanamide $^{N}$ \\
\hline evm.model.sctg_0079_0008.3 & Variable surface lipoprotein d1 \\
\hline evm.model.sctg_0122_0001.3 & ww rsp5 wwp \\
\hline
\end{tabular}

$\mathrm{N}$ indicates expression during the necrotrophic phase and $\mathrm{B}$ indicates expression during the biotrophic phase

protein, an integral membrane protein, a lactam utilization protein, a LEA domain-containing protein, a thaumatinlike protein, a transferase family protein and a urea hydrolase cyanamide protein. In the biotrophic phase a cell wall glycosyl hydrolase, a family 16 glycoside hydrolase and a NAD binding phosphogluconate dehydrogenate-like protein were upregulated (Additional file 1, AB intersect sheet). The pathogenic intersect (ABE) has 30 genes with known functions and these are shown in Table 5. The biotrophic intersect $(\mathrm{ABC})$ has 17 genes with putative functions (Table 6). RNA-Seq data revealed that most of $A B C$ and $A B E$ intersect genes are constitutively expressed (Additional file 1) at low to mid levels (adjusted means at 2 to 50 reads $=$ Low level; 50 to 125 reads $=$ mid level and $>125=$ high level of gene expression), with the exception of two genes from the $\mathrm{ABC}$ intersect, (a transcriptional family alpha/beta fold family protein and one hypothetical protein) that were differentially expressed in the necrotrophic phase (Additional file 1, $\mathrm{ABE}$ and $\mathrm{ABC}$ intersect sheets).
Table 5 Pathogenic intersect $A B E$ intersect pathogenic fungi

\begin{tabular}{ll} 
Gene Id & Gene annotation \\
\hline evm.model.sctg_0099_0004.5 & 3-dehydroquinate dehydratase \\
\hline evm.model.sctg_0005_0001.15 & $\begin{array}{l}\text { 4-carboxymuconolactone } \\
\text { decarboxylase }\end{array}$ \\
\hline evm.model.sctg_0024_0002.8 & 4-hydroxyphenylpyruvate dioxygenase \\
\hline evm.model.sctg_0220_0007.7 & Acetyltransferase \\
\hline evm.model.sctg_0108_0002.26 & Arylsulfatase \\
\hline evm.model.sctg_0002_0010.39 & Cupin domain protein \\
\hline evm.model.sctg_0004_0002.40 & Cytochrome c oxidase assembly protein \\
\hline evm.model.sctg_0029_0001.27 & Extracellular invertase \\
\hline evm.model.sctg_0040_0001.46 & Flavin-containing amine \\
\hline evm.model.sctg_0006_0005.98 & Formate nitrite transporter \\
\hline evm.model.sctg_0084_0003.26 & GAF domain nucleotide-binding \\
\hline evm.model.sctg_0289_0002.8 & Glycoside hydrolase family 45 protein \\
\hline evm.model.sctg_0089_0002.33 & gnat family acetyltransferase \\
\hline evm.model.sctg_0185_0001.1 & gpi-anchored protein \\
\hline evm.model.sctg_0040_0003.2 & Haloacid dehalogenase type ii \\
\hline evm.model.sctg_0346_0003.4 & Tubulin \\
\hline evm.model.sctg_0011_0002.41 & Iron permease ftr1 \\
\hline evm.model.sctg_0309_0002.8 & Minor histocompatibility antigen h13 \\
\hline evm.model.sctg_0002_0009.45 & Nitrilase 4 \\
\hline evm.model.sctg_0018_0008.47 & Nucleoside-diphosphate-sugar \\
\hline evm.model.sctg_0018_0007.18 & Phytanoyl-CoA dioxygenase \\
\hline family protein
\end{tabular}

\section{Identification of secreted proteins}

Because of the hemibiotrophic nature of $M$. roreri and the role that secreted proteins are expected to play in that interaction, we analyzed the genome for genes that express secreted proteins. The first screening identified all of the putative proteins with signal peptides. In $M$. roreri 1,752 proteins $(9.7 \%)$ were found to have signal peptides, which is slightly lower than M. perniciosa which has 1,810 proteins with signal peptides. Next the proteins with signal peptides were analyzed for transmembrane domains, to remove proteins that are expected to be incorporated into the membrane of the fungus. Ninety-two of the 1,752 proteins have two or more transmembrane 
Table 6 Biotrophic intersect

$\mathrm{ABC}$ intersect biotrophic fungi

\begin{tabular}{ll} 
Gene Id & Gene annotation \\
\hline evm.model.sctg_0063_0001.9 & $\begin{array}{l}\text { alpha- -mannosylglycoprotein 6-beta-n- } \\
\text { acetylglucosaminyltransferase a }\end{array}$ \\
\hline evm.model.sctg_0124_0001.10 & Aminoglycoside phosphotransferase \\
\hline $\begin{array}{l}\text { evm.model. } \\
\text { sctg_0007_0001.162 }\end{array}$ & $\begin{array}{l}\text { Dolichol phosphate-mannose biosynthesis } \\
\text { regulatory protein }\end{array}$ \\
\hline evm.model.sctg_0112_0002.7 & $\begin{array}{l}\text { dolichyl-phosphate mannosyltransferase } \\
\text { polypeptide 3 }\end{array}$ \\
\hline evm.model.sctg_0040_0002.2 & gas1-like protein \\
\hline evm.model.sctg_0016_0002.4 & Glycoside hydrolase family 61 protein \\
\hline evm.model.sctg_0063_0002.2 & Glycoside hydrolase family 95 protein \\
\hline evm.model. & Hydantoinase \\
sctg_0001_0002.138 & Hypothetical proline-rich protein \\
\hline evm.model.sctg_0919_0001.1 & Nuclear fusion protein kar5 \\
\hline evm.model.sctg_0166_0004.8 & Proteophosphoglycan 5 \\
\hline evm.model.sctg_0041_0003.8 & $\begin{array}{l}\text { Response regulator receiver } \\
\text { domain-containing protein }\end{array}$ \\
\hline evm.model.sctg_0231_0001.2 & Ribosomal protein I36 containing protein \\
\hline evm.model.sctg_0229_0001.10 & Transcription factor iib \\
\hline evm.model.sctg_0243_0004.11 & $\begin{array}{l}\text { Transcriptional family alpha beta fold } \\
\text { family protein }\end{array}$ \\
\hline evm.model.sctg_0005_0002.50 & Transmembrane protein 167a \\
\hline evm.model.sctg_0096_0003.37 & Vacuolar $\mathrm{h}+$-atpase assembly protein \\
\hline evm.model.sctg_0003_0004.13 & \\
\hline &
\end{tabular}

domains. One hundred and twenty-five glycosylphosphatidylinositol (GPI) anchor proteins were also excluded from the list of secreted proteins (Table 7). While the GPIanchored proteins are normally removed from secreted proteins, the posttranslational modification of glypiation is the only method of attachment to the membrane for these proteins, and because the bonds are subject to phospholipase cleavage, these proteins could still be released into the extracellular space via an enzymatic release process. After removal of proteins with transmembrane and GPI moieties the total number of $M$. roreri secreted proteins was 1,535 , which is less than the 1,596 secreted proteins predicted for M. perniciosa.

\section{Expression of the secretome}

In this study we wanted to verify the expression of the predicted genes, including the secretome identified in the genome analysis. We utilized a replicate set of infected pod tissues from a previous study to obtain transcriptomes representing the biotrophic and necrotrophic phases of the disease [21]. While our present focus is on the secreted proteins, the complete fungal transcriptome, for FPR, in different resistant plant backgrounds will be addressed in a separate treatise. The planting material used represents a segregating $\mathrm{F} 1$ population of progeny from highly susceptible clones (PA16 $\times$ SIC433 and PA16 $\times$ EEG29). Briefly, the pods used in this study were derived from flowers hand-pollinated 60 days prior to infection with a spore suspension of $1 \times 10^{8} \mathrm{M}$. roreri spores $\mathrm{ml}^{-1}$. The infected pods were frozen in liquid nitrogen and lyophilized at 30 days post infection (DPI) and at 60 DPI. Based on typical progression of FPR symptoms [21], three malformed green pods were selected for RNA-Seq and RT-qPCR from 30 DPI pods (biotrophic phase) and three necrotic sporulating pods were selected for RNA-Seq and RT-qPCR from 60 DPI pods (necrotrophic phase).

The 30 DPI pod samples yielded 67,818,927; 64,099,928 and 64, 033,574 reads and the number of fungal reads per sample were 149,675 (0.22\%), 122,289 (0.19\%) and 312,684 (0.49\%), respectively. For the 60 DPI pod samples 73 , 037,$363 ; 66,395,887$ and $69,434,845$ reads were sequenced, with fungal reads accounting for 603,498 (0.83\%), 882,821 (1.33\%) and 503,459 (0.73\%), respectively. When all of the libraries were compared 13,759 genes ( $77 \%$ of the predicted CDS) from the $M$. roreri genome were found to be expressed in these infected pods. The secreted proteins were then separated from the other expressed genes. Among the 1,535 secreted protein genes identified 1,355 or $88 \%$, were expressed at some level under the tested conditions. Using a P-value of 0.05 , we found that 222 of the secreted protein genes were differentially expressed between the 30 DPI and 60 DPI pods. All of the expressed secreted protein genes are listed in Additional file 2. The data revealed phase-dependent differential gene expression, where 164 of the genes were up-regulated in the 60 DPI pods while 58 were upregulated in the 30 DPI pods. Since the hypothetical genes can provided no information regarding their putative function they were eliminated from further consideration with regards to their role in the disease process.

Genes expressed during the early stages of infection and disease development reflect gene products that function in the biotrophic phase of the disease development, which can be initially asymptomatic. Late-stage gene expression

Table 7 Results of the genome based secretome analysis

\begin{tabular}{lcccccccc}
\hline & $\begin{array}{c}\text { total \# of } \\
\text { predicted } \\
\text { proteins }\end{array}$ & $\begin{array}{c}\text { Protein without } \\
\text { signal peptides }\end{array}$ & $\begin{array}{c}\text { Proteins with } \\
\text { signal peptides }\end{array}$ & $\begin{array}{c}\text { Proteins with } \\
\text { more than 2 } \\
\text { transmembrane } \\
\text { domains }\end{array}$ & $\begin{array}{c}\text { Proteins } \\
\text { with GPI } \\
\text { domains }\end{array}$ & $\begin{array}{c}\text { Total number of } \\
\text { secreted proteins } \\
\text { Minus TMD and } \\
\text { GPI domains }\end{array}$ & $\begin{array}{c}\text { \% proteins } \\
\text { with signal } \\
\text { peptides }\end{array}$ & $\begin{array}{c}\text { Unique } \\
\text { signal } \\
\text { peptides }\end{array}$ \\
\hline M. roreri & 17920 & 16167 & 1752 & 92 & 125 & 1535 & 9.7 & 39 \\
\hline M. perniciosa & 17016 & 15206 & 1810 & 92 & 122 & 1596 & 10.6 \\
\hline
\end{tabular}


yields gene products that function in the necrotrophic phase, which is associated with pod chlorosis and necrosis, and possibly with sporulation of the fungus on pod tissue. To validate the differential expression of genes encoding secreted proteins as suggested by the RNA-Seq analysis, RT-qPCR was conducted, with a selected number of genes comparing expression in a set of seven malformed green pods at $30 \mathrm{DPI}$ and seven necrotic pods at $60 \mathrm{DPI}$. At 30 DPI, 34 genes encoding secreted proteins with putative functions were expressed, with one being expressed only at this stage (Table 8). At 60 DPI, 105 genes encoding predicted secreted proteins with putative functions were expressed (Table 9). Forty-one of the 10560 DPI genes were detected only in the necrotrophic phase. RT-qPCR confirmed the up-regulation of the $30 \mathrm{DPI}$ and $60 \mathrm{DPI}$ genes (Tables 8 and 9). Although the GPI-anchored proteins were removed from the secretome we did find a number of them highly expressed in both the biotrophic and necrotrophic phases. Table 10 provides a list of the most highly expressed genes encoding GPI-anchored proteins in both phases since controlled release of these proteins from the fungal membrane is possible.

Several gene families of secreted proteins were prominently upregulated in the biotrophic phase. In this phase the 34 genes with known functions were primarily associated with nutrient acquisition and with plant and fungal cell wall modification. The largest single group identified was glycoside hydrolases $(\mathrm{GH})$. Eleven glycoside hydrolases genes were upregulated: two genes from $\mathrm{GH}$ family 5 ; five genes from GH family 18; and one gene each from the GH families 16, 28, 43, 92. The GH family 18 genes are homologous to chitinase genes (EC 3.2.1.14) [22] and GH family 5 genes are endo-enzymes that are capable of hydrolyzing both $\beta$-mannans and $\beta$-glucans [23] and are homologous to beta-1,3-glucanase, which includes endoglucanase, beta-mannanase, exo-1,3-glucanase, endo-1,6-glucanase, xylanase, and endoglycoceramidase. The GH $16 \mathrm{~s}$ are homologous to endobeta 1,3-glucanases (EC 3.2.1.39) and xyloglucan:xylogluosyltransferase (EC 2.4.1.207) [24], GH $28 \mathrm{~s}$ are homologous to polygalacturonases and includes pectin degrading enzymes like polygalacturonase (EC 3.2.1.15), exopolygalacturonase (EPG; EC 3.2.1.67), exopoly- $\alpha$-galacturonosidase (EC3.2.1.82) [25], GH $43 \mathrm{~s}$ are homologous to beta-xylosidases (EC 3.2.1.37) [26], while the GH $92 \mathrm{~s}$ are alpha-1,2-mannosidases [27] (Additional file 2). In addition to the GHs, other enzymes were identified such as galactose-1-epimerase, a carbonic anhydrase, a family 8 carbohydrate esterase (pectin methylesterase), and a tryptophan dimethylally transferase. The plant cell wall-modifying enzymes identified in the biotrophic phase include an endo-polygalacturonase, a galactan 1,3-beta-galactosidase, a cell wall glycosyl hydrolase, a catalase, an acetylxylan esterase and a xylanase A. Additionally, three cerato-platanin genes, two hydrophobins, three PR-1-like proteins, and an immunomodulatory protein were all induced in the biotrophic phase that could be involved in the fungal host interaction (Table 8).

Based on RNA-Seq and verified by RT-qPCR analysis, the majority of the genes within the 105 genes expressed during the necrotrophic phase are associated with fungal growth/ pathogenicity and nutrient acquisition. Several genes families were identified with multiple expressed genes such as hydrophobins (10 genes), FAD binding domain containing proteins (6 genes), aryl-alcohol oxidases (4 genes), laccases (4 genes), extracellular triacylglycerol lipases (3 genes) and cerato-platanins (3 genes). Several of these highly upregulated genes are associated with lignin breakdown. The arylalcohol oxidases (AAOs) are FAD containing extracellular enzymes in the glucose-methanol choline oxidase (GMC) family [28]. AAOs are involved in lignin degradation where the enzyme interacts with p-coumaryl alcohol, coniferyl alcohol and sinapyl alcohol polymers that make up the lignin, and $\mathrm{O}_{2}$ yielding aromatic aldehydes and hydrogen peroxide [28]. Laccases are polyphenol oxidases that reduce phenolic compounds in lignin [29]. Glyoxal oxidases are extracellular enzymes that form hydrogen peroxide during the breakdown of lignin [30]. Eight GH families were identified among the $12 \mathrm{GH}$ genes (two GH family 35 ; two GH family 61; two GH family 5 and one gene each for families 3, 9, 10, 16 and 18). The GH 35 s proteins are homologous to beta-galactosidases and $\mathrm{GH} 61$ s proteins are homologous to endoglucanases. The GH 3 s proteins are homologous to beta-glucosidases; GH 9 s proteins are endoglucanases or cellulases; and GH 10s proteins are xylanases [31]. Numerous other enzymes and pathogenicity-related genes were identified such as carboxypeptidases, carbohydrate esterases, tripeptidyl peptidase, a necrosis inducing protein, a fungal peroxidase, cytochrome p450s, and expansins. The highest relative expressions were found for a dioxygenase, a Fbox and FNIP repeat-containing protein, a chitin synthase, a proline-rich antigen and one of the expansins (Table 9).

Several gene families were found to be differently regulated and had specific members upregulated in the biotrophic phase and others upregulated in the necrotrophic phase. Of the 41 hydrophobin genes found in the genome, 12 were differentially expressed; 10 were upregulated in the necrotrophic phase; two in the biotrophic phase. Among the eight cerato-platanin genes found in the genome six were differentially upregulated; three in each phase. The expression of genes encoding fungal-derived pathogenesis-related proteins was detected in samples from the biotrophic phase, with $M r P R-1 n, M r P R-1 g$ and $M r P R-1 i 2$ being upregulated. Among the other nine genes encoding PR-1-like proteins found in the $M$. roreri genome, one $M r P R-1 d$ was upregulated in the necrotrophic phase and five were constitutively expressed under the tested conditions (Additional file 2). 
Table 8 Biotrophic gene Expression of putative Secreted Proteins

\begin{tabular}{|c|c|c|c|c|c|c|c|c|c|}
\hline \multirow[t]{3}{*}{ Transcript Id } & \multirow[t]{3}{*}{ Gene annotation } & \multicolumn{5}{|c|}{ RNAseq } & \multicolumn{3}{|c|}{ QPCR } \\
\hline & & \multirow{2}{*}{$\begin{array}{l}\text { 30DPI } \\
\text { Mean* }\end{array}$} & \multirow{2}{*}{$\begin{array}{l}\text { 60DPI } \\
\text { Mean* }\end{array}$} & \multirow[t]{2}{*}{ Pvalue } & \multirow[t]{2}{*}{ Fold change } & \multirow[t]{2}{*}{ Primers } & \multicolumn{2}{|c|}{$\begin{array}{l}\text { Induced } \\
\text { 30-60 DPI }\end{array}$} & $\begin{array}{l}\text { Repressed } \\
\text { 30-60 DPI }\end{array}$ \\
\hline & & & & & & & Mean & St. E. & $\overline{\text { Mean St. E. }}$ \\
\hline e.m.s_0369_0002.2 & Acetylxylan esterase & 638.4 & 91.6 & $5.8 \mathrm{E}-03$ & 7.0 & & & & \\
\hline e.m.s_0461_0001.1 & $\begin{array}{l}\text { Carbohydrate esterase } \\
\text { family } 8 \text { protein }\end{array}$ & 512.1 & 67.0 & $8.8 \mathrm{E}-04$ & 7.6 & MrCE8a & 20.868 & 8.9736 & \\
\hline e.m.s_0215_0001.21 & Carbonic anhydrase & 16.3 & 0.4 & $2.2 \mathrm{E}-02$ & & & & & \\
\hline e.m.s_0250_0003.8 & Catalase cat1 & 294.9 & 59.3 & $6.4 \mathrm{E}-03$ & 5.0 & MrCAT1 & 114.906 & 48.407 & \\
\hline e.m.s_0155_0004.13 & Cell wall glycosyl hydrolase & 330.4 & 26.3 & $7.4 \mathrm{E}-05$ & 12.6 & & & & \\
\hline e.m.s_0192_0001.1 & Cerato-platanin & 3014.0 & 520.7 & $5.3 \mathrm{E}-03$ & 5.8 & & & & \\
\hline e.m.s_0192_0003.14 & Cerato-platanin & 4931.3 & 968.5 & $7.2 \mathrm{E}-03$ & 5.1 & & & & \\
\hline e.m.s_0192_0003.17 & Cerato-platanin & 7602.6 & 912.5 & $7.1 \mathrm{E}-04$ & 8.3 & & & & \\
\hline e.m.s_0258_0001.1 & $\begin{array}{l}\text { Defense-related protein scp domain- } \\
\text { containing protein MrPR-1 g }\end{array}$ & 16778.8 & 1200.4 & $5.6 \mathrm{E}-04$ & 14.0 & $\mathrm{MrSCP}$ & 434.018 & 253.661 & \\
\hline e.m.s_0251_0004.1 & $\begin{array}{c}\text { Defense-related protein scp } \\
\text { domain-containing protein MrPR-1i2 }\end{array}$ & 32.6 & 2.4 & $7.4 \mathrm{E}-02$ & & & & & \\
\hline e.m.s_0516_0001.1 & $\begin{array}{c}\text { Defense-related protein scp } \\
\text { domain-containing protein Mr-PR-1n }\end{array}$ & 499.0 & 13.7 & $2.6 \mathrm{E}-06$ & 38.3 & & & & \\
\hline e.m.s_0041_0005.1 & Endo-polygalacturonase & 2621.4 & 32.4 & $1.4 \mathrm{E}-06$ & 81.9 & MrendoPG & 911.453 & 592.910 & \\
\hline e.m.s_0407_0004.2 & Galactan 1,3-beta-galactosidase & 37.6 & 52.2 & $2.4 \mathrm{E}-02$ & & & & & \\
\hline e.m.s_0027_0002.19 & Galactose 1-epimerase & 154.2 & 47.4 & $3.9 \mathrm{E}-02$ & 3.3 & & & & \\
\hline e.m.s_0011_0002.91 & Glycoside hydrolase family 16 protein & 1276.8 & 232.0 & $5.0 \mathrm{E}-03$ & 5.5 & & & & \\
\hline e.m.s_0030_0003.33 & Glycoside hydrolase family 18 protein & 6125.5 & 948.8 & $3.4 \mathrm{E}-03$ & 6.5 & MrGH18g & 38.900 & 16.126 & \\
\hline e.m.s_0044_0001.33 & Glycoside hydrolase family 18 protein & 527.3 & 56.3 & 7.7E-04 & 9.4 & MrGH18d & 253.832 & 183.817 & \\
\hline e.m.s_0044_0001.6 & Glycoside hydrolase family 18 protein & 12287.0 & 3336.6 & $2.1 \mathrm{E}-02$ & 3.7 & & & & \\
\hline e.m.s_0114_0002.6 & Glycoside hydrolase family 18 protein & 12684.6 & 687.6 & $5.1 \mathrm{E}-06$ & 18.5 & $\mathrm{MrGH} 18 \mathrm{C}$ & 151.387 & 51.810 & \\
\hline e.m.s_0416_0001.5 & Glycoside hydrolase family 18 protein & 4897.1 & 266.4 & $3.1 \mathrm{E}-06$ & 18.4 & & & & \\
\hline e.m.s_0055_0003.9 & Glycoside hydrolase family 28 protein & 129.2 & 20.9 & $1.3 \mathrm{E}-02$ & 6.1 & & & & \\
\hline e.m.s_0067_0006.17 & Glycoside hydrolase family 43 & 234.2 & 54.4 & $2.2 \mathrm{E}-02$ & 4.3 & & & & \\
\hline e.m.s_0043_0001.2 & Glycoside hydrolase family 5 protein & 3971.1 & 188.7 & $1.2 \mathrm{E}-06$ & 21.1 & & & & \\
\hline e.m.s_0531_0001.4 & Glycoside hydrolase family 5 protein & 3387.9 & 716.4 & $1.2 \mathrm{E}-02$ & 4.7 & $\mathrm{MrGH} 5$ & 69.7456 & 41.581 & \\
\hline e.m.s_0351_0003.10 & Glycoside hydrolase family 92 protein & 2935.9 & 894.7 & $4.6 \mathrm{E}-02$ & 3.3 & & & & \\
\hline e.m.s_0346_0003.2 & Hydrophobin 3 & 431.5 & 65.6 & $1.8 \mathrm{E}-03$ & 6.6 & $\mathrm{MrSc} 3 \mathrm{P} 3$ & 345.0789 & 196.349 & \\
\hline e.m.s_0346_0003.1 & Hydrophobin sc3-like & 6461.8 & 471.4 & $3.8 \mathrm{E}-05$ & 13.7 & $\mathrm{MrSc} 3 \mathrm{P} 2$ & 356.391 & 177.576 & \\
\hline e.m.s_0409_0005.4 & $\begin{array}{l}\text { Hypothetical fad dependent } \\
\text { oxidoreductase }\end{array}$ & 566.2 & 119.8 & $1.4 \mathrm{E}-02$ & 4.7 & & & & \\
\hline e.m.s_0561_0002.1 & Immunomodulatory protein & 7180.5 & 746.5 & $3.2 \mathrm{E}-04$ & 9.6 & & & & \\
\hline e.m.s_0095_0005.5 & $\begin{array}{l}\text { Major facilitator superfamily } \\
\text { multidrug-resistance }\end{array}$ & 7.0 & 0.0 & $1.3 \mathrm{E}-02$ & & & & & \\
\hline e.m.s_0053_0004.6 & $\begin{array}{l}\text { Membrane autotransporter } \\
\text { barrel domain protein }\end{array}$ & 755.7 & 203.5 & $2.5 \mathrm{E}-02$ & 3.7 & MrBDP & 5.184 & 1.528 & \\
\hline e.m.s_0094_0001.8 & O-methyltransferase & 1131.7 & 488.6 & $8.2 \mathrm{E}-04$ & & & & & \\
\hline e.m.s_0064_0001.5 & Tryptophan dimethylallyltransferase & 190.8 & 0.9 & $3.2 \mathrm{E}-04$ & 211.1 & MrTRY-DMA & 235.864 & 134.155 & \\
\hline e.m.s_0039_0002.43 & WSC domain protein & 356.0 & 102.1 & $4.1 \mathrm{E}-02$ & 3.5 & & & & \\
\hline e.m.s_0478_0002.2 & Xylanase A & 1135.8 & 9.0 & $9.3 \mathrm{E}-04$ & 126.0 & MrXYLa & 171.086 & 77.159 & \\
\hline
\end{tabular}

Mean* is the normalized mean based on the size factor of the libraries. 
Table 9 Necrotrophic genes expression of putative Secreted proteins

\begin{tabular}{|c|c|c|c|c|c|c|c|c|c|c|}
\hline \multirow[t]{3}{*}{ Transcript Id } & \multirow[t]{3}{*}{ Gene annotation } & \multicolumn{5}{|c|}{ RNAseq } & \multicolumn{4}{|c|}{ QPCR } \\
\hline & & \multirow{2}{*}{$\begin{array}{l}\text { 30DPI } \\
\text { Mean* }\end{array}$} & \multirow{2}{*}{$\begin{array}{l}\text { 60DPI } \\
\text { Mean* }\end{array}$} & \multirow[t]{2}{*}{ Pvalue } & \multirow[t]{2}{*}{ Fold change } & \multirow[t]{2}{*}{ Primers } & \multicolumn{2}{|c|}{ Induced 30-60 DPI } & \multicolumn{2}{|c|}{ Repressed 30-60 DPI } \\
\hline & & & & & & & Mean & St. E. & Mean & St. E. \\
\hline e.m.s_0228_0004.4 & Alpha beta hydrolase & 3.2 & 34.5 & $1.4 \mathrm{E}-02$ & 10.8 & & & & & \\
\hline e.m.s_0245_0001.13 & Alpha1,3-glucanase/mutanase & 0.7 & 171.8 & $8.3 \mathrm{E}-03$ & 245.4 & & & & & \\
\hline e.m.s_0185_0001.10 & Aryl-alcohol oxidase & 0.0 & 21.4 & $5.7 \mathrm{E}-04$ & 21.4 & & & & & \\
\hline e.m.s_0185_0001.9 & Aryl-alcohol oxidase & 0.0 & 7.8 & $4.2 \mathrm{E}-02$ & 7.8 & & & & & \\
\hline e.m.s_0274_0001.9 & Aryl-alcohol oxidase & 0.0 & 9.6 & $2.1 \mathrm{E}-02$ & 9.6 & & & & & \\
\hline e.m.s_0491_0001.5 & Aryl-alcohol oxidase & 3.9 & 61.7 & $3.0 \mathrm{E}-02$ & 15.9 & & & & & \\
\hline e.m.s_0100_0003.8 & Arylsulfatase & 2.6 & 42.4 & $2.9 \mathrm{E}-02$ & 16.4 & & & & & \\
\hline e.m.s_0251_0003.2 & Aspartic peptidase a1 & 11.5 & 46.7 & $3.6 \mathrm{E}-02$ & 4 & & & & & \\
\hline e.m.s_0056_0003.12 & Aspartic-type endopeptidase & 0.7 & 25.6 & $2.5 \mathrm{E}-03$ & 36.6 & & & & & \\
\hline e.m.s_0463_0001.8 & Beta-lactamase class penicillin binding protein & 6.6 & 324.6 & $1.5 \mathrm{E}-03$ & 492.4 & & & & & \\
\hline e.m.s_0066_0001.46 & Biotrophy-associated secreted protein 2 MrBAS1 & 7.6 & 496.7 & $1.0 \mathrm{E}-03$ & 66.1 & MrSP2a & & & 26.509 & 15.802 \\
\hline e.m.s_0005_0005.16 & Biotrophy-associated secreted protein 2 MrBAS2 & 2.0 & 613.6 & $3.2 \mathrm{E}-04$ & 322.6 & & & & & \\
\hline e.m.s_0227_0001.20 & Calcineurin-like phosphoesterase & 1.8 & 19.0 & $9.5 \mathrm{E}-03$ & 10.6 & & & & & \\
\hline e.m.s_0066_0001.21 & Carbohydrate esterase family 4 protein & 0.7 & 83.8 & $1.8 \mathrm{E}-02$ & 119.7 & & & & & \\
\hline e.m.s_0155_0002.4 & Carbohydrate esterase family 4 protein & 0.0 & 50.5 & $2.1 \mathrm{E}-06$ & 50.5 & & & & & \\
\hline e.m.s_0008_0001.25 & Carbonic anhydrase & 0.7 & 121.3 & $7.0 \mathrm{E}-08$ & 172.8 & & & & & \\
\hline e.m.s_0190_0004.1 & Carboxypeptidase cpds & 3.8 & 460.0 & $4.4 \mathrm{E}-07$ & 121.1 & & & & & \\
\hline e.m.s_0190_0004.2 & Carboxypeptidase cpds & 3.1 & 28.5 & $5.1 \mathrm{E}-03$ & 9.2 & & & & & \\
\hline e.m.s_0176_0001.14 & Cellulose-binding protein & 0.0 & 22.2 & 4.7E-04 & 22.2 & & & & & \\
\hline e.m.s_0058_0002.19 & Cerato platanin & 0.0 & 16.2 & $3.2 \mathrm{E}-03$ & 16.2 & & & & & \\
\hline e.m.s_0058_0002.21 & Cerato-platanin & 2.1 & 36.2 & $2.7 \mathrm{E}-02$ & 18.1 & & & & & \\
\hline e.m.s_0192_0001.2 & Cerato-platanin & 0.0 & 20.7 & $7.5 \mathrm{E}-04$ & 20.7 & & & & & \\
\hline e.m.s_0192_0001.6 & Cerato-platanin & 0.0 & 494.9 & $2.2 \mathrm{E}-04$ & 494.9 & & & & & \\
\hline e.m.s_0297_0002.3 & Chitin deacetylase family 4 & 0.0 & 40.4 & $2.8 \mathrm{E}-02$ & 40.5 & MrCHIDACTb & & & 5663.095 & 3460.583 \\
\hline e.m.s_0245_0001.24 & Chitin synthase & 0.0 & 2158.9 & $2.8 \mathrm{E}-04$ & 2159 & $\mathrm{MrCHS}$ & & & 2515.177 & 1862.483 \\
\hline e.m.s_0008_0004.19 & Copper amine oxidase & 4.3 & 77.0 & $6.6 \mathrm{E}-03$ & 17.9 & & & & & \\
\hline e.m.s_0003_0001.85 & Cutinase & 0.0 & 9.5 & $2.3 \mathrm{E}-02$ & 9.5 & & & & & \\
\hline e.m.s_0017_0003.61 & Cytochrome p450 & 0.0 & 32.2 & $9.1 \mathrm{E}-03$ & 32.2 & & & & & \\
\hline e.m.s_0052_0004.10 & Cytochrome p450 & 0.7 & 14.9 & $3.2 \mathrm{E}-02$ & 21.1 & & & & & \\
\hline e.m.s_0470_0001.6 & Cytochrome p450 monooxygenase & 5.0 & 91.2 & $1.1 \mathrm{E}-04$ & 18.3 & MrCp450a & & & 30.050 & 11.8905 \\
\hline e.m.s_0059_0001.14 & Deuterolysin m35 metalloprotease & 2.8 & 137.0 & $5.0 \mathrm{E}-02$ & 48.9 & & & & & \\
\hline e.m.s_0099_0003.13 & Dioxygenase family protein & 8.3 & 5904.3 & $3.6 \mathrm{E}-02$ & 715.6 & & & & & \\
\hline
\end{tabular}


Table 9 Necrotrophic genes expression of putative Secreted proteins (Continued)

\begin{tabular}{|c|c|c|c|c|c|c|c|c|}
\hline e.m.s_0061_0002.41 & Exo-beta 1,3-glucanase & 2.6 & 16.7 & $4.4 \mathrm{E}-02$ & 6.4 & & & \\
\hline e.m.s_0026_0005.53 & Expansin family protein & 0.0 & 1165.0 & $9.8 \mathrm{E}-04$ & 1165 & MrEXP-A & 326.810 & 159.020 \\
\hline e.m.s_0086_0003.2 & Expansin family protein & 1.8 & 37.3 & $2.6 \mathrm{E}-04$ & 20.7 & & & \\
\hline e.m.s_0280_0002.5 & Extracellular dioxygenase & 0.0 & 15.1 & $3.4 \mathrm{E}-03$ & 15.1 & & & \\
\hline e.m.s_0107_0002.16 & Extracellular triacylglycerol lipase precursor & 0.0 & 9.8 & $2.0 \mathrm{E}-02$ & 9.8 & & & \\
\hline e.m.s_0107_0002.18 & Extracellular triacylglycerol lipase precursor & 0.0 & 9.8 & $2.3 \mathrm{E}-02$ & 9.8 & & & \\
\hline e.m.s_0352_0003.3 & Extracellular triacylglycerol lipase precursor & 0.0 & 9.7 & $2.1 \mathrm{E}-02$ & 9.7 & & & \\
\hline e.m.s_0054_0001.12 & FAD binding domain protein & 31.7 & 306.9 & $2.3 \mathrm{E}-04$ & 9.7 & & & \\
\hline e.m.s_0135_0001.27 & FAD binding domain-containing protein & 0.0 & 43.9 & $6.4 \mathrm{E}-06$ & 43.9 & & & \\
\hline e.m.s_0277_0002.12 & FAD binding domain-containing protein & 6.5 & 91.2 & $1.1 \mathrm{E}-04$ & 14.1 & & & \\
\hline e.m.s_0277_0002.13 & FAD binding domain-containing protein & 2.6 & 124.8 & $1.1 \mathrm{E}-04$ & 48 & & & \\
\hline e.m.s_0375_0001.9 & FAD binding domain-containing protein & 2.0 & 85.8 & $9.5 \mathrm{E}-06$ & 43.1 & & & \\
\hline e.m.s_0459_0001.6 & FAD binding domain-containing protein & 0.0 & 36.5 & $3.2 \mathrm{E}-04$ & 36.5 & & & \\
\hline e.m.s_0469_0001.4 & FAD binding domain-containing protein & 0.0 & 8.4 & 3.7E-02 & 8.4 & & & \\
\hline e.m.s_0002_0010.20 & F-box and fnip repeat-containing protein & 114.0 & 3336.6 & $2.1 \mathrm{E}-02$ & 29.3 & & & \\
\hline e.m.s_0087_0002.1 & Fruit-body specific gene a & 0.7 & 20.9 & 7.7E-03 & 29.8 & & & \\
\hline e.m.s_0053_0004.14 & Fungal peroxidase & 3.6 & 22.3 & $1.5 \mathrm{E}-02$ & 6.3 & & & \\
\hline e.m.s_0111_0006.5 & Glucooligosaccharide oxidase & 0.0 & 27.8 & $8.3 \mathrm{E}-03$ & 27.8 & & & \\
\hline e.m.s_0211_0001.14 & Glucose oxidase & 0.0 & 66.0 & $3.6 \mathrm{E}-07$ & 66 & & & \\
\hline e.m.s_0085_0002.37 & Glycoside hydrolase family 16 protein & 0.0 & 30.0 & 7.7E-05 & 29 & & & \\
\hline e.m.s_0021_0002.67 & Glycoside hydrolase family 18 protein & 19.6 & 87.3 & $5.0 \mathrm{E}-02$ & 4.5 & & & \\
\hline e.m.s_0261_0004.2 & Glycoside hydrolase family 3 protein & 25.4 & 127.4 & $1.7 \mathrm{E}-02$ & 5 & & & \\
\hline e.m.s_0008_0004.3 & Glycoside hydrolase family 30 protein & 11.7 & 67.7 & 3.7E-02 & 6 & & & \\
\hline e.m.s_0232_0001.2 & Glycoside hydrolase family 35 protein & 33.9 & 128.7 & $4.3 \mathrm{E}-02$ & 3.8 & & & \\
\hline e.m.s_0438_0002.3 & Glycoside hydrolase family 35 protein & 0.0 & 19.7 & 8.7E-04 & 19.7 & & & \\
\hline e.m.s_0007_0001.127 & Glycoside hydrolase family 5 protein & 27.1 & 163.4 & $5.6 \mathrm{E}-03$ & 6 & & & \\
\hline e.m.s_0265_0002.8 & Glycoside hydrolase family 5 protein & 10.8 & 111.9 & $5.4 \mathrm{E}-05$ & 10.4 & & & \\
\hline e.m.s_0241_0001.11 & Glycoside hydrolase family 61 protein & 0.0 & 26.6 & $9.6 \mathrm{E}-03$ & 26.6 & & & \\
\hline e.m.s_0241_0001.12 & Glycoside hydrolase family 61 protein & 0.0 & 43.1 & $5.9 \mathrm{E}-03$ & 43.1 & & & \\
\hline e.m.s_0155_0002.8 & Glycoside hydrolase family 61 protein & 13.5 & 115.5 & $1.3 \mathrm{E}-02$ & 8.6 & & & \\
\hline e.m.s_0004_0003.50 & Glycoside hydrolase family 9 protein & 10.4 & 63.2 & $8.9 \mathrm{E}-03$ & 6.3 & $\mathrm{MrGH} 9$ & 4.311 & 1.827 \\
\hline e.m.s_0200_0003.3 & Glycosyl hydrolase family 10 & 0.7 & 22.6 & $3.6 \mathrm{E}-02$ & 32.2 & & & \\
\hline e.m.s_0333_0001.1 & Glyoxal oxidase & 4.9 & 47.9 & $5.1 \mathrm{E}-03$ & 9.8 & & & \\
\hline e.m.s_0135_0001.28 & gmc oxidoreductase & 14.3 & 52.2 & $2.4 \mathrm{E}-02$ & 3.6 & & & \\
\hline
\end{tabular}


Table 9 Necrotrophic genes expression of putative Secreted proteins (Continued)

\begin{tabular}{|c|c|c|c|c|c|c|c|c|}
\hline e.m.s_0074_0003.10 & Hemerythrin hhe cation binding domain-containing protein & 49.9 & 383.1 & $2.1 \mathrm{E}-02$ & 7.7 & & & \\
\hline e.m.s_0039_0002.15 & Hemolysin & 0.7 & 16.1 & $2.3 \mathrm{E}-02$ & 22.9 & & & \\
\hline e.m.s_0062_0001.18 & Heterokaryon incompatibility protein het-c & 28.2 & 116.3 & $1.5 \mathrm{E}-02$ & 4.1 & & & \\
\hline e.m.s_0018_0008.40 & Hydrophobin & 13.2 & 86.6 & $3.6 \mathrm{E}-02$ & 6.6 & & & \\
\hline e.m.s_0018_0008.54 & Hydrophobin & 0.7 & 61.9 & $1.2 \mathrm{E}-05$ & 87.1 & & & \\
\hline e.m.s_0018_0008.56 & Hydrophobin & 0.0 & 256.2 & $4.3 \mathrm{E}-12$ & 256 & MrLM18 & 1573.702 & 1268.272 \\
\hline e.m.s_0058_0002.53 & Hydrophobin & 0.7 & 25.1 & $2.8 \mathrm{E}-03$ & 35.7 & & & \\
\hline e.m.s_0058_0002.55 & Hydrophobin & 9.0 & 304.7 & $5.8 \mathrm{E}-07$ & 34.2 & & & \\
\hline e.m.s_0149_0001.14 & Hydrophobin & 0.0 & 11.2 & $1.2 \mathrm{E}-02$ & 11.2 & & & \\
\hline e.m.s_0149_0001.16 & Hydrophobin & 0.0 & 425.5 & $2.3 \mathrm{E}-06$ & 425.6 & MrLM19 & 257.737 & 133.646 \\
\hline e.m.s_0170_0002.12 & Hydrophobin & 0.0 & 9.3 & $2.4 \mathrm{E}-02$ & 9.3 & & & \\
\hline e.m.s_0298_0001.2 & Hydrophobin & 0.0 & 11.4 & $1.2 \mathrm{E}-02$ & 11.4 & & & \\
\hline e.m.s_0149_0001.15 & Hydrophobin 2 & 0.0 & 205.6 & $1.6 \mathrm{E}-04$ & 205.6 & & & \\
\hline e.m.s_0199_0001.3 & Laccase & 0.0 & 9.6 & $2.6 \mathrm{E}-02$ & 9.6 & & & \\
\hline e.m.s_0210_0002.8 & Laccase & 0.0 & 119.6 & $1.0 \mathrm{E}-06$ & 119.6 & & & \\
\hline e.m.s_0246_0002.7 & Laccase & 1.3 & 41.0 & $1.0 \mathrm{E}-02$ & 31.8 & & & \\
\hline e.m.s_0279_0002.3 & Laccase & 0.0 & 21.1 & $3.4 \mathrm{E}-02$ & 21.2 & & & \\
\hline e.m.s_0082_0001.16 & Mannoprotein & 88.8 & 298.1 & 4.7E-02 & 3.4 & & & \\
\hline e.m.s_0030_0003.64 & Metalloproteinase & 18.6 & 306.9 & $8.1 \mathrm{E}-06$ & 16.5 & & & \\
\hline e.m.s_0406_0002.4 & Necrosis inducing-like protein npp1 type & 9.1 & 658.2 & $1.5 \mathrm{E}-04$ & 73.1 & MrNPP1 & 310.949 & 181.890 \\
\hline e.m.s_0051_0003.3 & nhl repeat-containing protein & 0.0 & 28.8 & $1.1 \mathrm{E}-04$ & 28.8 & & & \\
\hline e.m.s_0120_0002.7 & Oxalate decarboxylase & 9.3 & 57.9 & $4.8 \mathrm{E}-02$ & 6.2 & & & \\
\hline e.m.s_0398_0002.11 & Oxidoreductase fad binding & 1.8 & 111.0 & $5.4 \mathrm{E}-04$ & 61.6 & & & \\
\hline e.m.s_0639_0001.6 & Para-nitrobenzyl esterase & 0.0 & 45.8 & $3.2 \mathrm{E}-04$ & 45.8 & & & \\
\hline e.m.s_0082_0001.36 & Peptidase m28 & 3.2 & 57.6 & $3.9 \mathrm{E}-02$ & 18 & & & \\
\hline e.m.s_0007_0001.138 & Peptide-n4-(n-acetyl-beta-glucosaminyl)asparagine amidase a & 0.0 & 12.6 & $3.5 \mathrm{E}-02$ & 12.5 & & & \\
\hline e.m.s_0180_0002.16 & Phosphatidylserine decarboxylase & 4.3 & 451.8 & $5.1 \mathrm{E}-04$ & 105.1 & & & \\
\hline e.m.s_0432_0001.5 & PR-1 protein MrPR-1d & 5.8 & 45.1 & $1.4 \mathrm{E}-03$ & 7.8 & & & \\
\hline e.m.s_0568_0001.7 & Proline-rich antigen & 7.7 & 1372.5 & 7.7E-03 & 177.3 & & & \\
\hline e.m.s_0018_0003.1 & Proline-specific peptidase & 29.2 & 94.0 & $5.0 \mathrm{E}-02$ & 3.2 & & & \\
\hline e.m.s_0726_0001.2 & Pyrolysin & 8.1 & 50.9 & $3.5 \mathrm{E}-02$ & 6.3 & & & \\
\hline e.m.s_0125_0001.43 & Riboflavin aldehyde-forming enzyme & 61.2 & 229.9 & $3.8 \mathrm{E}-02$ & 3.8 & & & \\
\hline e.m.s_0040_0001.30 & Ribonuclease t1 & 0.0 & 11.4 & $1.1 \mathrm{E}-02$ & 11.4 & & & \\
\hline e.m.s_0321_0001.8 & Serine-rich protein & 16.4 & 289.5 & $5.2 \mathrm{E}-04$ & 18.1 & MrSRP & 14.072 & 5.613 \\
\hline
\end{tabular}


Table 9 Necrotrophic genes expression of putative Secreted proteins (Continued)

\begin{tabular}{|c|c|c|c|c|c|c|c|c|}
\hline e.m.s_0005_0005.47 & Serine-type endopeptidase & 224.0 & 811.1 & $4.1 \mathrm{E}-02$ & 3.6 & MrS-endo & 3.482 & 0.866 \\
\hline e.m.s_0021_0002.36 & Tripeptidyl peptidase A & 0.0 & 20.8 & $6.5 \mathrm{E}-04$ & 20.8 & & & \\
\hline e.m.s_0166_0004.10 & Tripeptidyl peptidase A & 1.8 & 39.5 & $1.8 \mathrm{E}-04$ & 21.9 & & & \\
\hline e.m.s_0048_0003.5 & Virus P4 KP4 toxin & 0.0 & 118.9 & $4.5 \mathrm{E}-02$ & 119 & MrKP4 & 134.442 & 52.042 \\
\hline e.m.s_0014_0002.14 & wsc domain-containing protein & 0.0 & 42.6 & $8.7 \mathrm{E}-06$ & 42.6 & & & \\
\hline e.m.s_0010_0002.57 & Zinc metalloprotease & 10.7 & 92.8 & $2.6 \mathrm{E}-03$ & 8.7 & & & \\
\hline
\end{tabular}

Mean* is the normalized mean based on the size factor of the libraries. 
Table $10 \mathrm{GPI}$ anchor proteins

\begin{tabular}{|c|c|c|c|c|}
\hline \multirow[t]{2}{*}{ Gene Id } & \multirow[t]{2}{*}{ Gene name } & \multirow{2}{*}{$\begin{array}{l}\text { 30DPI } \\
\text { Mean* }\end{array}$} & \multirow{2}{*}{$\begin{array}{l}60 \text { DPI } \\
\text { Mean* }\end{array}$} & \multirow[t]{2}{*}{ Pvalue } \\
\hline & & & & \\
\hline evm.model.sctg_0115_0006.6 & Related to tgf beta induced protein ig-h3 precursor & 1303.93 & 283.09 & $1.03 \mathrm{E}-02$ \\
\hline evm.model.sctg_0044_0002.3 & Chitin deacetylase 9 & 330.81 & 98.49 & 4.34E-02 \\
\hline evm.model.sctg_0035_0002.62 & gmc oxidoreductase & 15.03 & 10883.07 & $3.48 \mathrm{E}-03$ \\
\hline evm.model.sctg_0474_0002.6 & gmc oxidoreductase & 1.99 & 6162.70 & 1.85E-04 \\
\hline evm.model.sctg_0154_0003.4 & Nucleus protein & 21.52 & 377.01 & $1.01 \mathrm{E}-05$ \\
\hline evm.model.sctg_0023_0002.46 & Aspartic peptidase a1 & 5.89 & 793.02 & $5.90 \mathrm{E}-05$ \\
\hline evm.model.sctg_0233_0003.16 & gmc oxidoreductase & 12.78 & 268.23 & $9.28 \mathrm{E}-03$ \\
\hline evm.model.sctg_0090_0005.3 & Aspartic peptidase a1 & 4.60 & 105.14 & 4.91E-05 \\
\hline evm.model.sctg_0003_0001.29 & Carbohydrate esterase family 4 protein & 81.65 & 240.08 & 4.51E-02 \\
\hline evm.model.sctg_0470_0001.4 & Carbohydrate esterase family 4 protein & 23.70 & 94.23 & $1.66 \mathrm{E}-02$ \\
\hline evm.model.sctg_0007_0001.101 & Extracellular serine-rich & 264.05 & 1547.88 & 2.37E-03 \\
\hline evm.model.sctg_0016_0004.31 & Glycoside hydrolase family 16 protein & 0.70 & 17.08 & 1.66E-02 \\
\hline evm.model.sctg_0061_0002.53 & Glycosyl hydrolase 53 domain-containing protein & 2.80 & 87.42 & $2.18 \mathrm{E}-02$ \\
\hline evm.model.sctg_0069_0001.19 & Glyoxal oxidase & 15.69 & 92.15 & $3.58 \mathrm{E}-02$ \\
\hline evm.model.sctg_0233_0003.16 & gmc oxidoreductase & 12.78 & 268.23 & $9.28 \mathrm{E}-03$ \\
\hline evm.model.sctg_0149_0001.6 & Macrofage activating glycoprotein & 5.38 & 47.41 & 4.89E-02 \\
\hline evm.model.sctg_0149_0001.5 & Macrofage activating glycoprotein & 1.99 & 59.62 & 1.07E-04 \\
\hline evm.model.sctg_0154_0003.4 & Nucleus protein & 21.52 & 377.01 & $1.01 \mathrm{E}-05$ \\
\hline evm.model.sctg_0020_0001.30 & Serine-threonine rich & 92.38 & 614.18 & 4.02E-03 \\
\hline
\end{tabular}

Mean* is the normalized mean based on the size factor of the libraries.

\section{Discussion}

\section{Genome comparison}

We have produced a high-quality draft genome of $M$. roreri using different next-generation sequencing technologies. After sequence assembly using the whole genome shotgun (WGS) strategy, a total of 3,298 contigs with a N50 value of $48.1 \mathrm{~kb}$ was assembled with a total genome size calculated to be $52.3 \mathrm{Mbp}$. Although larger, the $M$. roreri genome is structurally and organizationally similar to M. perniciosa, a sister taxa with a draft genome consisting of 3,087 contigs $(\mathrm{N} 50=48 \mathrm{~kb})$ and a genome size of $44.7 \mathrm{Mbp}$. The majority of the size difference between the genomes is associated with repetitive DNA. The $M$. roreri genome size is larger than the genome of $M$. perniciosa, but the number of genes located in each genome is similar.

One factor for the size difference between $M$. roreri and $M$. perniciosa is highly correlated to the difference in the number of Long Terminal Repeat-Transposable Elements (LTR-TEs) between the genomes. About $3.46 \mathrm{Mbp}$ or approximately $7 \%$ of the $M$. roreri genome is attributed to LTR-TEs located in the genome, while only $0.332 \mathrm{Mbp}$ or about $1 \%$ of the M. perniciosa genome is attributed to LTRTEs. Transposable Elements (TEs) contribute no more than 10 to $15 \%$ in most fungal taxa [32]. For example, the Saccharomyces cereviseae genome contains $3.1 \%$ TEs [33], the Magnaporthe oryzae genome ranges from $8.2-14 \%$ [34], while $24 \%$ of the Laccaria bicolor genome is transposon derived [35]. Within the $M$. perniciosa genome these repetitive elements are active and appear to contribute to the genetic variability of the species [20]. Another factor contributing to the size difference between the genomes is associated with repetitive elements and low complexity DNA. $M$. roreri genome has four times as many repetitive elements $(7,060,129 \mathrm{bp})$ as found in the $M$. perniciosa genome $(1,737,865 \mathrm{bp})$. The classification and biological roles of these repetitive sequences and transposable elements in $M$. roreri are beyond the scope of this discussion but will be explored in depth in a separate treatise.

The high degree of similarity between $M$. roreri and M. perniciosa genomes supports their taxonomic relatedness, while distinctions have been identified that could contribute to their distinctive functional and morphologic differences. Bidirectional blast analysis of $M$. roreri with four other basidiomycetes revealed a set of 1,133 genes specific to $M$. roreri. The majority of these genes are hypothetical with only 16 genes having known homologies and most of these relate to TEs. Expression analysis of the A gene set (genes specific to $M$. roreri) revealed that only seven of these genes are expressed and all at low levels. Among the genes encoding hypothetical proteins that are specific to $M$. roreri, 129 were constitutively expressed and only three were differentially expressed in both the biotrophic and necrotrophic phases (Additional file 1, A set 
sheet). Low to mid-level constitutive expression in genes from the $A B E$ and $A B C$ intersects (Tables 5 and 6) suggest that these genes are used in general functions common to the sampled basidiomycetes such as metabolism. The differential expression of the 14 genes shared by $M$. roreri and $M$. perniciosa ( $\mathrm{AB}$ intersect) in the biotrophic and necrotrophic phases, as expression of these genes suggests similarities in the hemibiotrophic life cycle of these species.

\section{Secretome targeting the plant cell}

RNA-Seq, was used to validate the genome CDS through transcriptome expression analysis of $M$. roreri infected cacao pods at $30 \mathrm{DPI}$ and $60 \mathrm{DPI}$. These two sampling points compare genes expressed in the early stage or biotrophic phase and the late stage or necrotrophic phase of the FPR disease cycle. In silico analysis of genes with signal peptides, which have a high likelihood of being transported outside of the fungus, yielded 1,355 genes expressed at some level in the 30 and 60 DPI samples, as detected by RNA-Seq. Only 222 of these genes were differentially expressed between the biotrophic and necrotrophic phases, using a P-value of 0.05 . The similarities in gene expression between the two phases are greater than the dissimilarities. For example, genes encoding plant cell wall-degrading cellulases were not upregulated in the biotrophic phase, but, their expression was detected. Although the functions of many of these genes are unknown their expression raises the potential that they serve critical roles in the $M$. roreri life cycle.

Many of the known secreted protein encoding genes that were upregulated in the biotrophic phase encode for putative glycoside hydrolases $(\mathrm{GH})$ that act on oligosaccharides making up the plant cell wall. Of the 34 differentially expressed secreted protein genes associated with the biotrophic phase, 11 were glycoside hydrolases from six families of hydrolases, which enables $M$. roreri to interact with the different biochemical components of plant cell walls. This diverse array of polysaccharide degrading enzymes could function together with other hemicelluloses-degrading enzymes, such as those that hydrolyze xylan. All of these polysaccharide degrading enzymes appear to work in concert to loosen the connections between the plant cells, releasing nutrients that can be utilized by the fungus. Pectin is another major component of the intercellular matrix of the cacao pod husk [36]. M. perniciosa, the causal agent of WBD on cacao, has been observed to express genes for pectin lyase and pectin methylesterases during infection of parthenocarpic pods [18]. In FPR, pectin is also under attack during the biotrophic phase of $M$. roreri. Genes encoding pectin degrading enzymes are upregulated in this phase.

The biotrophic phase of $M$. roreri is a complex stage requiring controlled cell wall degradation and modification, allowing the invasion of the pod while the fungus remains substantially undetected by plant defenses. All of the $M$. roreri genes encoding plant cell wall enzymes that are induced in the biotrophic phase are able to attack the matrix of the intercellular space. This interaction likely facilitates penetration and spread of the fungus between cells without eliciting major responses from the plant.

In contrast, the expression pattern of genes encoding secreted proteins during the necrotrophic phase of $M$. roreri suggest a more aggressive breakdown of plant structures and the upregulation of aryl-alcohol oxidases, laccases, and a glyoxal oxidase gene during the necrotrophic phase suggests that $M$. roreri, targets lignin for breakdown during the necrotrophic phase. This evidence is further supported by the fact that three of the four aryl alcohol oxidases and three of the four laccases genes are exclusively expressed during the necrotrophic phase (Table 9) [28-30]. There are other upregulated enzymes that may also have a role in these ligninolytic reactions such as a fungal peroxidase, a copper amine oxidase and two dioxygenases. Fungal peroxidases were induced in $M$. perniciosa under nutrient limited conditions [18], while intradiol dioxygenase was shown to be induced in $M$. roreri during necrotrophy in a prior study [21].

Similar to the biotrophic phase, eight glycoside hydrolase $(\mathrm{GH})$ families were also induced in the necrotrophic phase. Although the specific details concerning the exact function of these $\mathrm{GH}$ families of genes are lacking, it is interesting to note the differential expression patterns between the biotrophic and necrotrophic phases. GH families shared with the biotrophic phase include families 5, 16 and 18. GH families 28, 43 and 92 are unique to the biotrophic phase, whereas families 3, 9, 10, 35, and 61 are unique to the necrotrophic phase. The $\mathrm{GH}$ families unique to the necrotrophic phase include enzymes involved in the degradation of plant cell walls into compounds that the fungus can consume. Complex stage-specific regulation of genes targeting plant cell walls in association with the biotroph/necrotroph shift was also observed in hemibiotrophic Colletotrichum species [37]. The differential expression of genes with seemingly related functions provides the opportunity to fine tune aspects of growth and development to the changing conditions and requirements of the two phases of FPR.

Other cell surface-modifying enzymes upregulated in the necrotrophic phase are triacylglycerol lipase precursors and a cutinase suggesting lipid breakdown and modification of the protective surfaces of the plant cells. A necrosis inducing-like protein (NLP) that could be responsible for cell death and nutrient leakage was also found to be up-regulated [38]. NLPs have been identified in many pathogenic associations such as WBD and other biotrophic interactions [39-41]. Two genes from another class of virulence genes, biotrophy-associated secreted proteins BAS (MrBAS1 and MrBAS2) are highly 
expressed in the $M$. roreri necrotrophic phase. These effector proteins have been shown to accumulate in the biotrophic interface region for the ascomycete Magnaporthe grisea [42]; however, their roles in the necrotrophic phase of this interaction are yet to be determined. At the same time in the necrotrophic phase, multiple extracellular peptidases are being upregulated possibly in response to the proteins and peptides that are now available from the necrotic plant cells [43]. Specific activities of $M$. roreri associated with the necrotrophic phase appear to target cell wall and membrane breakdown in associations with enzymes that are linked with the switch of this fungus from biotrophic to necrotrophic phase. The differentially expressed secretome of the necrotroph suggests conditions for rapid growth of the fungus, where plant lignocellulosic cell walls are being degraded and multiple plant components are being released and are available to be used by the fungus as nutrients. The need for stealth has been removed and nutrient acquisition is predominantly to support the rapid growth associated with the necrotrophic phase [21].

\section{Secretome targeting modification of the fungal cell wall} There is no evidence that haustoria or other cell wallpenetrating structures are formed during the biotrophic phase of $M$. roreri. The slow-growing $M$. roreri mycelia of the biotrophic phase are large pleomorphic cells that fill the spaces between the plant cells [21]. This abnormal mycelial growth habit does have some similarity to haustoria-like structures, although they are outside the cell wall and, possibly provide the fungus with more surface area for cell-to-cell interactions and exchange of metabolites. The necrotrophic mycelia are profuse and grow rapidly in necrotic tissues [21]. These mycelia are thin and elongated. The sporophores and resulting spores represent a second fungal morphology associated with the necrotrophic phase. Genes encoding proteins that are functional in and on the fungal cell wall were differentially expressed between the phases of FPR. Often unique members of the same gene family were differentially expressed.

\section{Chitin synthesis and modification}

There were five differentially expressed family 18 glycoside hydrolases associated with the biotrophic phase and one associated with the necrotrophic phase. These chitinolytic enzymes could be modifying the chitin structure and the surface of the mycelia. These modifications could protect the mycelia from plant defenses such as plant chitinases [44], thus allowing the fungus to grow intercellularly. Several chitinases are highly expressed in cacao pod tissues throughout development, and can be hyper-induced in response to $M$. roreri infection [21]. Another possibility is that the chitinases attack chitin oligosaccharides released from the fungus, after being attacked by plant chitinases. Additional extracellular chitinases could help eliminate these chitin oligosaccharides and prevent the elicitation of plant defense responses [45].

A chitin deacetylase and a chitin synthase were highly upregulated in the necrotrophic phase. The induction of chitin synthase is consistent with the rapid growth of the fungus initiated during the necrotrophic phase. The chitin deacetylase and related enzymes like exo-beta-glucanases and family 4 carbohydrate esterases can modify chitin, either loosening the chitin polymer bonds or converting the chitin to chitosan. Like the rust fungus Uromyces viciae-faba [46], $M$. roreri may use chitin deacetylase and other enzymes to modify its own cell wall reducing the effectiveness of the plant enzymes. A resistant wall structure may be particularly important in the harsh environment created as plant tissues die. Although cacao defense genes were induced in the later stages of the biotrophic phase of FPR, their induction levels continued to increase once the necrotrophic phase has been initiated [21].

\section{$P R-1$ related proteins}

Pathogenesis-related 1 proteins (PR-1) are a class of plant genes induced by pathogens during the infection stage and they are partially responsible for systemic acquired resistance responses in those plants. It is of particular interest that plant-like defense proteins would be found in a pathogen and within two species of the same fungal genus. Of the 12 PR- 1 related genes identified in the $M$. roreri genome, 10 have homology to PR-1 genes recently described in Moniliophthora perniciosa [47]. Three of these PR-1-like proteins are upregulated during the biotrophic phase, five are constitutively expressed and only $\mathrm{MrPr}$-1d was upregulated in the necrotrophic phase. All of the MrPR-1-like proteins have the SCP/TAPS-like conserved domains (Figure 3). The $M r P R-1 g$ and $M r P R-1 a$ match the expression of their homologs in the biotrophic phase of $M$. perniciosa [47]. Also of interest is the Cterminal extension of the $M r P R-1 g$ protein, which is found in both $M$. perniciosa and $M$. roreri and could have a specific protein-protein mediated function as purposed by Teixeira et al., [47]. The MrPR-1b homolog was constitutively expressed in $M$. roreri, which differs from the case of $M$. perniciosa where it was upregulated in the necrotrophic phase. While the exact function of these PR-1 proteins in fungi is unknown, these fungal-derived PR-1 like proteins may be masking the fungal cell wall from plant defense mechanisms, or they may bind to them preventing their activity. Riviere et al., [48] demonstrated that $P R-1 a$ proteins in tobacco plants regulate the extracellular enzyme activity of $\beta$-(1-3)-glucanase activity and plants with PR-1 silenced genes had higher enzyme levels along with a decrease in the deposition of $\beta-(1-3)$ glucans and callose. Callose deposition in the cell-wall sheath around the plasmodesmata openings is a dynamic regulator mechanism that appears to 


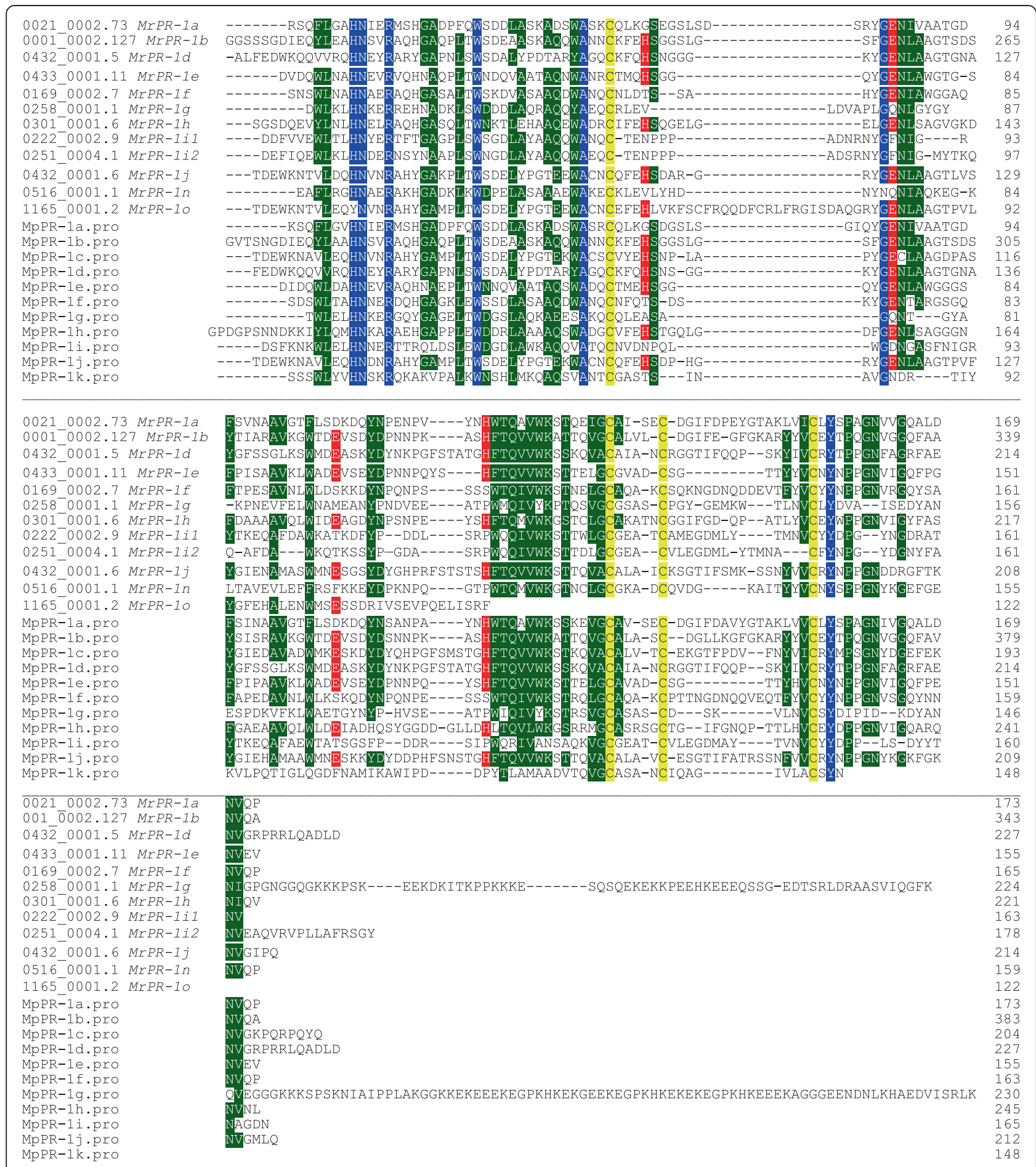

Figure 3 PR-1 Alignment of the conserved SCP/TAPS protein domains. Similarities are shown for the PR-1 like-proteins from Moniliophthora roreri and Moniliophthora perniciosa. Most of the sequences similarities are within the SCP/TAPS domain region. Conserved amino acids are highlighted with blue representing 100\% identity and green representing at least a $60 \%$ identity. The putative active sites in these proteins are highlighted in red and the conserved cysteines are highlighted in yellow. 
alter the size of the plasmodesmata orifice, which in turn can modify cell to cell transport by restricting the size of transport molecules [49]. Previous work has shown that $M$. roreri infected cacao pods at 30 DPI have a 1.6 to 2 fold reduction in glucose, phenylalanine and asparagine levels [21], which suggests the fungus has access to these plant metabolites, despite being limited to the intercellular spaces. During the necrotrophic phase (60 DPI) most pod metabolites are severely depleted. The $M$. roreri mycelia, which grow between plant cells, may have access to the plasmodesmata passages and the nutrients that pass through them. The PR-1 like proteins appear to be important to virulence, and it has been suggested that they support systemic spread of the fungus, possibly by limiting susceptibility to host defenses, or they may act as effectors suppressing host defenses [50]. The phase specific expression of the different PR-1 encoding genes is interesting, particularly because of the difference in the host interactions of the biotroph and necrotroph. The PR-1 proteins expressed by $M$. roreri in the different phases could be acting to alter the plant cell walls or as competitive inhibitors of plant PR-1 proteins, thus minimizing the plant defense response, or they could have antimicrobial activity, which would function to prevent subsequent infection and development of competing microorganisms.

\section{Hydrophobins}

Of the 41 hydrophobins found in the genome, three members of the hydrophobin gene family are up-regulated in the biotrophic phase and 10 members are up regulated in the necrotrophic phase. The hydrophobins interact at the fungal cell surface creating a hydrophobic surface layer and are important in many morphogenetic processes such as sporulation, fruiting body formation and infection structures [51]. Hydrophobins are grouped into three classes Ia, Ib, and II, with Ia and II occurring in ascomycetes and Ib in basidiomycetes [52]. These proteins have the unique ability to self assemble once secreted and they function at the fungal wall-air interface, limiting desiccation and providing protection against both chemical and enzymatic attack [53]. It is easy to postulate the need for different hydrophobins between the two phases of FPR, considering the need to limit detection in the biotrophic phase and the need to protect the surface from enzymatic and chemical attack in the necrotrophic phase. In animal systems at least, hydrophobins are known to prevent host recognition of pathogen-associated molecular patterns, thus preventing the activation of host immune response [54]. Hydrophobins are also of interest because of their potential uses in industrial processes [52].

\section{Cerato-platanins and related proteins}

Three cerato-platanin (CP) genes are up-regulated in the biotroph and four are upregulated in the necrotroph.
Cerato-platanin domain-containing proteins such as EPL (eliciting plant response-like), Snodprot, swollenins and expansins have a double $\psi \beta$-barrel fold and a carbohydrate binding site that have been shown to induce plant defense response $[55,56]$. Cerato-platanins can cause nutrient leakage and cell death in cacao $[57,58]$. Ectopic expression of the Magnaporthe grisea CP gene, MgSM1, upregulates the expression of plant defense genes such as PR-1, PR-5 and PDF1.2 and induces local hypersensitivity reactions (HR) [59]. This class of fungal proteins is called elicitors or effector proteins. A fungal effector protein found in Colletotrichum truncatum (CtCP1) is expressed during the infection stage [60]. Unlike the MgMS1 protein, CtCP1 does not cause HR or elicit a plant defense response, [60] demonstrating that the activity of cerato-platanins can be both host and protein specific. An EPL gene from Trichoderma species produces a protein that binds to chitin and self assembles at the air/water interface like a hydrophobin [61]. When MSP1, a snodprot1 homolog protein, was knocked out in Magnaporthe oryzae, the fungus was unable to grow within the plant after normal infection suggesting this protein has a key function during the intercellular growth of this fungus [62]. Other CP-family proteins such as snodprot1 homologs are expressed in ecotomycorrhizal fungi Pisolithus microcarpus and Laccaria bicolor [63], suggesting a role for this family of genes during the plant fungal interaction.

Two expansins were upregulated in the necrotrophic phase of this study. Expansins were first discovered in plants, due to their role in developmental processes involving cell wall modifications, including cell enlargement, by "loosening" plant cell walls [64]. A functional expansin family protein was reported in the basidiomycete Bjerkandera adusta [65], and expansin-like proteins have been reported in other fungi, including plant pathogens. Brotman et al. [66] reported swollenin, an expansin family protein, in Trichoderma that is involved in colonization of plant roots and apparently elicits plant-defense responses. The expansin-like and cerato-platanin proteins may be involved in invasion and pathogenesis of plant tissues by phytopathogens that employ penetration of host/susceptible tissues. Since members of the cerato-platanin family are highly expressed in both phases of FPR, it further supports scenarios in which the fungus uses unique members of complex gene families to facilitate growth and spreading under the conditions unique to each phase.

Another indicator of the biotrophic/necrotrophic switch is the upregulation of several genes in the necrotrophic phase that are associated with fungal reproduction such as the heterokaryon incompatibility protein, a fruiting bodyspecific gene and a riboflavin aldehyde-forming enzyme. The reproductive stage of the fungus occurs after the necrotrophic phase and is a nutrient intensive process 
[13]. Cytochrome P450s and hydrophobins have been previously found in necrotic cacao pods infected with FPR [21] and have been shown to be expressed during fungal reproduction, specifically in the fruiting body development $[53,67]$. However, unlike most basidiomycetes, $M$. roreri has lost the ability to form a basdiocarp or mushroom and sporulates directly from the mycelial mat that it forms on the diseased pod [13].

\section{Conclusion}

The $M$. roreri genome and expression analyses provide insight into the molecular mechanisms of the biotrophic and necrotrophic phases of this important hemibiotrophic pathogen. RNA-Seq analysis revealed differential gene expression during the biotrophic and necrotrophic phases of $M$. roreri during the development of FPR disease of cacao. Focusing on the secreted proteins found in this genome, we observed specific secreted proteins putatively involved in plant cell wall degradation in the biotrophic phase, which seem to degrade and utilize the intercellular spaces. At the same time, they appear to be masking or modifying the fungal cell surface to avoid plant defenses, allowing the fungus to colonize the pod. In contrast, other secreted proteins upregulated in the necrotrophic phase suggest that the fungus continues to protect its mycelia from plant defenses, while actively releasing enzymes and toxins that have been reported to attack the plant cell wall components and utilizing plant nutrients that are released during plant cell death. These findings support the existing pathogenesis model for FPR while giving greater details regarding the identity of putative secreted proteins involved in the different stages, and information regarding the differential use of unique members of complex gene families. Due to the high number of genes that encode hypothetical proteins in this genome and that are expressed during the disease process more research is needed to fully understand the various phases of this hemibiotrophic fungus.

\section{Methods}

Biological material, libraries construction and sequencing The $M$. roreri clone (MCA2977) was isolated from the state of Los Rios in Ecuador. It was grown and maintained on a yeast extract $\left(5 \mathrm{gL}^{-1}\right)$ and glycerol $\left(20 \mathrm{~mL} \mathrm{~L}{ }^{-1}\right)$ medium. Cultures were incubated at $27^{\circ} \mathrm{C}$ at $200 \mathrm{rpm}$ for $7 \mathrm{~d}$. Total DNA was extracted using a cetyl trimethylammonium bromide (CTAB) method [68].

\section{Genome assembly}

Moniliophthora roreri DNA sequences were obtained by a hybrid sequencing approach using GS FLX and Illumina sequencing, and the whole-genome shotgun strategy. The GS FLX sequencer (454 Life Sciences/Roche) was used to produce $3,440,399$ single-end reads with a mean length of $230 \mathrm{bp}$ and 417,891 reads from paired end runs with $2 \mathrm{Kbp}$ insert size. An Illumina Genome Analyzer was used to produce $30,826,974$ read pairs $(2 \times 76 \mathrm{bp}$, insert size of $365 \mathrm{bp}$ ). The Illumina data was filtered to remove reads from mitochondrial genome and plasmids. Illumina data was error-corrected using Quake v0.3 with default parameters. In total, 24,405,509 read pairs passed Quake error correction. The final hybrid assembly of both 454 data and Illuminia data was performed by using the Newbler v.2.6 assembler (default parameters with overlap parameter $>=40$ and identity to $>=95 \%$, http://www. 454 . com/products/analysis-software/) $[69,70]$.

\section{Combined gene models}

\section{Ab-initio gene models prediction}

Genefinding prediction programs, Genemark-ES v2.3 [71] and Augustus v2.3.1 [72,73] programs optimized with the Exonerate v2.2.0 protein2genome model [74] were used to perform the ab-initio gene prediction. Genefinding prediction program Genemark.hmm [75] was executed in self-training mode and ORFs larger than 200 bp were retained. The Genemak-ES predicted proteins were aligned against the GenBank NR, using BLASTP with a e-value cutoff of 1e-10. Finally, EVidence Modeller (EVM) [76] was used to combine the predictions from Genemark-ES, Augustus and Exonerate spliced protein alignments and generate a consensus gene prediction. Select gene models were manually inspected, especially incomplete genes $5^{\prime}$ and 3 ' ends of the scaffold.

\section{Automatic annotation}

The automatic annotation program AutoFACT [77] was used for functional annotation of gene models. The main contribution of AutoFACT is the capacity to conduct the annotation based on sequence similarity searches in several databases. For this, we used the BLASTp (e-value cutoff of 1e-5) to align the gene models against various proteins databases: non-redundant (NR) database at NCBI, SwissProt-databases containing only manually curated proteins [78], uniref90 and uniref100-databases containing clustered sets of proteins from UniProt, Pfam-database of proteins families [79] and KEGG-database of metabolic pathways [80]. Open reading frames were also annotated using Blast2GO (http://www.blast2go.com/b2ghome) [81].

\section{Transposable elements}

The $M$. roreri and $M$. perniciosa genomes were scanned for transposable elements. Each genome was fragmented in silico into 1000-bp fragments. These fragments were compared to a database of full length LTR retroptransposons developed by the program LTR struc [82] of LTRs associated with $M$. roreri and $M$. perniciosa using the BLAST program. Fragments with significant E-values (E-04) and 
better were sequestered. The rest of the fragments with no hits to LTR retrotransposons were scanned against the repbase database [83], which is a collection of sequences representing repetitive DNA from different eukaryotic species using the Blast program.

The $M$. roreri and $M$. perniciosa genomes were also scanned for repeptive DNA using the program Repeat Masker with full Repbase. However, this scan did not find all the LTR and repetitive elements. Thus, repeat Modeler was also used to find denovo repeats and used as the database for input into Repeat Masker. This analysis is shown (Additional file 1 Repeat modeler sheet) RepeatMasker Open-3.0. <http://www.repeatmasker.org>.

\section{Transcriptome}

\section{Transcriptome analysis in infected pods}

Briefly, the pods used in this study were derived from flowers hand pollinated 60 days prior to infection with a spore suspension of $1 \times 10^{8}$ spores $\mathrm{ml}^{-1}$ [21]. The plant material used was a segregating F1 population of progeny from highly susceptible clones (PA16 $\times$ SIC433 and PA16 $\times$ EEG29). Seven infected pods were frozen in liquid nitrogen at 30 days post infection (DPI) and another seven at $60 \mathrm{DPI}$. Based on the typical progression of FPR symptoms [21], malformed green pods were selected for RNA-Seq and RT-qPCR from 30 DPI pods which represents the biotrophic phase. Necrotic sporulating pods were selected for RNA-Seq and RT-qPCR from 60 DPI pods, which represents the necrotrophic phase.

\section{RNA extraction}

Each infected pod was broken up and coarsely ground under liquid nitrogen and approximately $1 \mathrm{~cm}^{3}$ was used for processing. The pod material was ground finely and transferred to a disposable $50 \mathrm{~mL}$ centrifuge tube containing $15 \mathrm{~mL}$ of $65^{\circ} \mathrm{C}$ extraction buffer [84]. Additional extraction methods were conducted as in Melnick et al. [18]. The cDNA was synthesized using the Invitrogen (Carlsbad, CA) Superscript VILO kit, following the manufacturer's directions.

\section{RNA sequencing}

For the genome-wide analyses of expression patterns, cDNA was generated using a routine RNA library preparation TruSeq protocol developed by Illumina Technologies (San Deigo, CA). Using the kit, mRNA was first isolated from total RNA by performing polyA selection step, followed by construction of single end sequencing libraries with an insert size of $160 \mathrm{bp}$. Single-end sequencing was performed on six samples (three 30 DPI and three 60 DPI) using the Illumina HiSeq platform. Samples were multiplexed with unique six-mer barcodes generating 404,820,524 filtered (for Illumina adapters/primers, and PhiX contamination) $1 \times 50$ bp paired end reads.

\section{Expression analysis}

Reads from 30 DPI and 60 DPI libraries were mapped to the nucleotide sequences of predicted protein coding genes of the $M$. roreri genome using the short read aligner Bowtie-0.12.7 which utilizes a Burrows-Wheeler index [85]. Count data were obtained for each coding sequence. Estimation and statistical analysis of expression levels using count data of each gene with 3 replicates for each library was performed using the DEseq package [86] and R x64 2.15.2 program. (http://www.r-project.org/).

After RNA-Seq, twenty five genes were chosen for analysis by RT-qPCR across the full set of infected pods. For RT-qPCR analysis, seven replicate malformed green pods $30 \mathrm{DPI}$ and seven replicate necrotic sporulating pods (60 DPI) were used. RT-qPCR analysis was conducted following Bailey et al. [21], using Brilliant III ${ }^{\odot}$ SYBR $^{\circ}$ Green Q-PCR Master Mix (Agilent, Santa Clara, CA). Primer sources, sequences for the $M$. roreri genes are in Additional file 3. M. roreri ESTs were chosen based upon results of RNA-Seq analysis. RT-qPCR was conducted to determine the changes in expression of $M$. roreri genes between the biotrophic and necrotrophic phases of FPR. The ddCt method was used to calculate the foldchange between the 30 and 60 day DPI samples $[87,88]$.

\section{Statistical analysis of data}

A two-way ANOVA of the RNA-Seq data was conducted using the general linear model (PROC GLM) followed by Tukey post-hoc testing $(\alpha=0.05)$ using SAS 9.3 (SAS Institute Inc., Raleigh, NC, USA) to analyze pod data. For RT-qPCR, relative transcript levels were determined following Pfaffl [89].

\section{Secreted proteins}

17,920 protein coding sequences were scanned for signal peptides using signalP $[90,91]$. The resulting proteins containing signal peptides were scanned for transmembrane proteins using the TMHMM program (Prediction of transmembrane helices in proteins) [92]. Proteins with no more than two transmembrane domains were sequestered for further analysis. The resulting proteins were scanned for GPI-anchored proteins [93,94] using FragAnchor, which is based on the tandem use of a Neural Network predictor and a Hidden Markov Model predictor (http://navet.ics. hawaii.edu/ fraganchor/NNHMM/NNHMM.html) [95]. Proteins that were highly probably and probable of having a GPI-anchor were discarded. Thus, using bioinformatics, proteins with signal peptides, with two or less transmembrane domains and without GPI-anchors were considered for possible secretion.

\section{Venn diagram}

Using a bi-directional blast method the $M$. roreri, $M$. perniciosa, Laccaria bicolor, Coprinus cinereus, and Ustilago 
maydis genomes were compared and used to generate a 5-way Venn diagram. In addition, five tax plots for all five fungal species were created using each genome as a reference, respectively. Protein sequences that share an expected E-value of E-04 were considered matches.

\section{Dot plots}

Dot plots between the large contigs (50,000 bp or larger) of $M$. roreri and M. perniciosa were created using the whole genome aligner MUMmer3.22. The NUCmer and MUMmerplot programs from the MUMmer suite were used $[96,97]$.

\section{Availablity of supporting data}

This M. roreri Whole Genome Shotgun project has been deposited at DDBJ/EMBL/GenBank under the accession AWSO00000000. The version described in this paper is version AWSO01000000. The sequencing data used in this study can be found under NCBI BioProjects. BioProject PRJNA213737 is linked to the genome data and PRJ NA229176 was established for the transcriptome data.

\section{Additional files}

Additional file 1: This file contains the Repeat Modeler file and a complete list of the Venn diagram intersects; $A, A B, A B C$ and $A B E$ discussed in the text. There is a sheet for each set and intersect and RNA-Seq data are provided for each gene in that intersect.

Additional file 2: This file contains the complete list of the 1535 secreted genes and the $125 \mathrm{GPI}$-anchor containing proteins identified in the $\boldsymbol{M}$. roreri genome. The file contains RNA-Seq data for each gene and RT-qPCR data for a number of selected genes. The corresponding M. perniciosa homolog is also listed with the homology E-value.

Additional file 3: This file contains the complete set of RT-qPCR primers used in this study. The file provides the primer name, nucleotide sequence, $M$. roreri gene Id, PCR fragment size and the nucleotide sequence for each fragment.

\section{Abbreviations}

M. roreri: Moniliophthora roreri; M. perniciosa: Moniliophthora perniciosa FPR: Frosty Pod Rot; CDS: Coding sequences; OFRs: Open reading frames; RNA-seq: RNA sequencing; WBD: Witches' broom disease; Mbp: Million base pairs; NLP: Necrosis inducing-like protein; NP-50: Statistical measure of average length of contigs in a Draft sequence.

\section{Competing interests}

The authors declare that they have no competing interests.

\section{Author's contributions}

LWM conceived the study, participated in its design and coordination, ARS lead and drafted the manuscript. GGLC participated in the sequence alignment and bioinformatic analysis of the genome. DPTT sequence analysis and helped to draft the manuscript. PJPLT sequence analysis and helped to draft the manuscript. MFC participated in the sequence alignment and bioinformatic analysis of the genome. SCS conducted 454 sequencing and participated in the sequence alignment. JEC conducted 454 sequencing and participated in the sequence alignment. MJG participated in its design and coordination of the study, PSU lead. PM conducted Illumina sequencing and participated in the sequence alignment. AF conducted RNA sequencing and bioinformatics analysis. TR conducted RNA sequencing and bioinformatics analysis. JC conducted field studies, collected samples and participated in the statistical analysis of data. RED sequence analysis and helped to draft the manuscript. JS participated in the sequence alignment, bioinformatic analysis of the RNA-seq data and helped to draft the manuscript. RLM carried out molecular genetic studies, participated in the statistical analysis of data and helped to drafted the manuscript. GAGP participated in its design and coordination of the study, Brazilian lead. BAB conceived the study, participated in its design and coordination, carried out molecular genetic studies and helped to draft the manuscript. All authors read and approved the final manuscript.

\section{Acknowledgements}

This work was funded by USDA ARS. We would like to acknowledge the contributions of the Center for Computational Engineering and Sciences at UNICAMP SP Brazil (FAPESP/CEPID project \#2013/08293-7). References to a company and/or product by the USDA are only for the purposes of information and do not imply approval or recommendation of the product to the exclusion of others that may also be suitable. The U.S. Department of Agriculture (USDA) prohibits discrimination in all its programs and activities on the basis of race, color, national origin, age, disability, and where applicable, sex, marital status, familial status, parental status, religion, sexual orientation, genetic information, political beliefs, reprisal, or because all or part of an individual's income is derived from any public assistance program. (Not all prohibited bases apply to all programs.) Persons with disabilities who require alternative means for communication of program information (Braille, large print, audiotape, etc.) should contact USDA's TARGET Center at (202) 720-2600 (voice and TDD). To file a complaint of discrimination, write to USDA, Director, Office of Civil Rights, 1400 Independence Avenue, S.W., Washington, D.C. 20250-9410, or call (800) 795-3272 (voice) or (202) 720-6382 (TDD). USDA is an equal opportunity provider and employer.

\section{Author details}

${ }^{1}$ Sustainable Perennial Crops Lab, USDA/ARS, Bldg 001 Rm 223 Beltsville Agricultural Research Center-West, Beltsville, MD 20705, USA. ${ }^{2}$ Centro Nacional de Processamento de Alto Desempenho em São Paulo, Universidade Estadual de Campinas, CP 6141, Campinas 13083-970, SP, Brazil. ${ }^{3}$ Laboratório de Genômica e Expressão, Departamento de Genética, Evolução e Bioagentes, Instituto de Biologia, Universidade Estadual de Campinas (UNICAMP), CP 6109, Campinas 13083-970, SP, Brazil. ${ }^{4}$ Center for Infectious Disease Dynamics, Pennsylvania State University, University Park, PA 16802, USA. ${ }^{5}$ Department of Ecosystem Science and Management, Pennsylvania State University, University Park, PA 16802, USA. 'Department of Horticulture, Pennsylvania State University, University Park, PA 16802, USA. ${ }^{7}$ Department of Genetics, School of Medicine, University of North Carolina at Chapel Hill, Mary Ellen Jones, Room 921, 27599-3280 Chapel Hill, NC, USA. ${ }^{8}$ National Center of Genomic Research, 2935 Rodeo Park Drive East Santa Fe, NM 87505 Santa Fe, USA. ${ }^{9} \mathrm{CABI}$ Bioscience UK Centre, Egham, UK. ${ }^{10}$ Molecular Plant Pathology Lab, USDA/ARS, Bldg 004 Rm 119 Beltsville Agricultural Research Center West, Beltsville, MD 20705, USA.

Received: 29 September 2013 Accepted: 14 February 2014

Published: 27 February 2014

\section{References}

1. Latunde-Dada AO: Colletotrichum: tales of forcible entry, stealth, transient confinement and breakout. Mol Plant Pathol 2001, 2(4):187-198.

2. Oliver RP, Ipcho SVS: Arabidopsis pathology breathes new life into the necrotrophs-vs.-biotrophs classification of fungal pathogens. Mol Plant Pathol 2004, 5(4):347-352.

3. Catanzariti AM, Dodds PN, Lawrence GJ, Ayliffe MA, Ellis JG: Haustorially expressed secreted proteins from flax rust are highly enriched for avirulence elicitors. Plant Cell 2006, 18(1):243-256.

4. Link TI, Voegele RT: Secreted proteins of Uromyces fabae: similarities and stage specificity. Mol Plant Pathol 2008, 9(1):59-66.

5. Brown NA, Antoniw J, Hammond-Kosack KE: The predicted secretome of the plant pathogenic fungus Fusarium graminearum: a refined comparative analysis. Plos One 2012, 7(4):e33731.

6. Thomma BP: Alternaria spp.: from general saprophyte to specific parasite. Mol Plant Pathol 2003, 4(4):225-236.

7. Evans HC, Stalpers JA, Samson RA, Benny GL: Taxonomy of Monilia-Roreri, an important pathogen of theobroma-cacao in South-America. Can J Bot 1978, 56(20):2528-2532. 
8. Aime MC, Phillips-Mora W: The causal agents of witches' broom and frosty pod rot of cacao (chocolate, Theobroma cacao) form a new lineage of Marasmiaceae. Mycologia 2005, 97(5):1012-1022.

9. Phillips-Mora W, Wilkinson MJ: Frosty pod of cacao: a disease with a limited geographic range but unlimited potential for damage. Phytopathology 2007, 97(12):1644-1647.

10. Meinhardt LW, Rincones J, Bailey BA, Aime MC, Griffith GW, Zhang DP, Pereira GAG: Moniliophthora perniciosa, the causal agent of witches' broom disease of cacao: what's new from this old foe? Mol Plant Pathol 2008, 9(5):577-588

11. Ferreira LFR, Duarte KMR, Gomes LH, Carvalho RS, Leal GA, Aguiar MM, Armas RD, Tavares FCA: Genetic diversity of polysporic isolates of Moniliophthora perniciosa (Tricholomataceae). Genet Mol Res 2012 11(3):2559-2568

12. Phillips-Mora W, Wilkinson MJ: Frosty pod: a disease of limited geographic distribution but unlimited potential for damage. Phytopathology 2006, 96(6):S138-S138

13. Evans HC: Pod Rot of Cacao caused by Moniliophthora (Monilia) roreri. 24th edition. London: Commonwealth Agricultural Bureau; 1981.

14. Joosten M, de Wit P: THE TOMATO-CLADOSPORIUM FULVUM INTERACTION: a versatile experimental system to study plant-pathogen interactions. Annu Rev Phytopathol 1999, 37:335-367.

15. Perfect SE, Green JR: Infection structures of biotrophic and hemibiotrophic fungal plant pathogens. Mol Plant Pathol 2001, 2(2):101-108.

16. Scarpari LM, Meinhardt LW, Mazzafera P, Pomella AWV, Schiavinato MA, Cascardo JCM, Pereira GAG: Biochemical changes during the development of witches' broom: the most important disease of cocoa in Brazil caused by Crinipellis perniciosa. J Exp Bot 2005, 56(413):865-877.

17. Melnick RL, Marelli J, Bailey BA: The molecular interaction of Theobroma cacao and Moniliophthora perniciosa, causal agent of witches' broom, during infection of young pods. Phytopathology 2011, 101(6):S274-S274.

18. Melnick RL, Marelli JP, Sicher RC, Strem MD, Bailey BA: The interaction of Theobroma cacao and Moniliophthora perniciosa, the causal agent of witches' broom disease, during parthenocarpy. Tree Genet Genomes 2012 8(6):1261-1279.

19. Thomazella DP, Teixeira PJ, Oliveira HC, Saviani EE, Rincones J, Toni IM, Reis O, Garcia O, Meinhardt LW, Salgado I, Pereira, GA: The hemibiotrophic cacao pathogen Moniliophthora perniciosa depends on a mitochondrial alternative oxidase for biotrophic development. New Phytol 2012, 194(4):1025-1034.

20. Mondego JM, Carazzolle MF, Costa GG, Formighieri EF, Parizzi LP, Rincones J, Cotomacci C, Carraro DM, Cunha AF, Carrer H, Vidal, RO, Estrela RC, Garcia O, Thomazella DPT, de Oliveira BV, Pires ABL, Rio MCS, Araujo MRR, de Moraes MH, Castro LAB, Gramacho KP, Goncalves MS, Neto JPM, Neto AG, Barbosa LV, Guiltinan MJ, Bailey BA, Meinhardt LW, Cascardo JCM, Pereira GAG: A genome survey of Moniliophthora perniciosa gives new insights into Witches' Broom disease of cacao. Bmc Genomics 2008, 9:548.

21. Bailey BA, Crozier J, Sicher RC, Strem MD, Melnick R, Carazzolle MF, Costa GGL, Pereira GAG, Zhang DP, Maximova S, Guiltinan M, Meinhardt L: Dynamic changes in pod and fungal physiology associated with the shift from biotrophy to necrotrophy during the infection of Theobroma cacao by Moniliophthora roreri. Physiol Mol Plant P 2013, 81:84-96.

22. Henrissat B: A classification of glycosyl hydrolases based on amino acid sequence similarities. Biochem J 1991, 280(Pt 2):309-316.

23. Dias FM, Vincent F, Pell G, Prates JA, Centeno MS, Tailford LE, Ferreira LM Fontes CM, Davies GJ, Gilbert HJ: Insights into the molecular determinants of substrate specificity in glycoside hydrolase family 5 revealed by the crystal structure and kinetics of Cellvibrio mixtus mannosidase 5A. J Biol Chem 2004, 279(24):25517-25526.

24. Fibriansah G, Masuda S, Koizumi N, Nakamura S, Kumasaka T: The $1.3 \mathrm{~A}$ crystal structure of a novel endo-beta-1,3-glucanase of glycoside hydrolase family 16 from alkaliphilic Nocardiopsis sp. strain F96. Proteins 2007, 69(3):683-690.

25. Markovic $\mathrm{O}$, Janecek $\mathrm{S}$ : Pectin degrading glycoside hydrolases of family 28: sequence-structural features, specificities and evolution. Protein Eng 2001, 14(9):615-631.

26. Vandermarliere $\mathrm{E}$, Bourgois $\mathrm{TM}$, Winn MD, van Campenhout $\mathrm{S}$, Volckaert $\mathrm{G}$, Delcour JA, Strelkov SV, Rabijns A, Courtin CM: Structural analysis of a glycoside hydrolase family 43 arabinoxylan arabinofuranohydrolase in complex with xylotetraose reveals a different binding mechanism compared with other members of the same family. Biochem J 2009, 418(1):39-47.
27. Tiels P, Baranova E, Piens K, De Visscher C, Pynaert G, Nerinckx W, Stout J, Fudalej F, Hulpiau P, Tannler S, Geysens S, Van Hecke A, Valevska A, Vervecken W, Remaut $H$, Callewaert N: A bacterial glycosidase enables mannose-6-phosphate modification and improved cellular uptake of yeast-produced recombinant human lysosomal enzymes. Nat Biotechnol 2012, 30(12):1225-1231

28. Ferreira P, Hernandez-Ortega A, Herguedas B, Martinez AT, Medina M: Aryl-alcohol oxidase involved in lignin degradation: a mechanistic study based on steady and pre-steady state kinetics and primary and solvent isotope effects with two alcohol substrates. J Biol Chem 2009, 284(37):24840-24847.

29. Mayer AM, Staples RC: Laccase: new functions for an old enzyme. Phytochemistry 2002, 60(6):551-565.

30. Kersten PJ: Glyoxal oxidase of Phanerochaete chrysosporium: its characterization and activation by lignin peroxidase. Proc Natl Acad Sci U S A 1990, 87(8):2936-2940

31. Henrissat B, Callebaut I, Fabrega S, Lehn P, Mornon JP, Davies G: Conserved catalytic machinery and the prediction of a common fold for several families of glycosyl hydrolases. Proc Natl Acad Sci U S A 1995, 92(15):7090-7094.

32. Wostemeyer J, Kreibich A: Repetitive DNA elements in fungi (Mycota): impact on genomic architecture and evolution. Curr Genet 2002, 41(4):189-198

33. Goffeau A, Barrell BG, Bussey H, Davis RW, Dujon B, Feldmann H, Galibert F, Hoheisel JD, Jacq C, Johnston M, Louis EJ, Mewes HW, Murakami Y, Philippsen P, Tettelin H, Oliver SG: Life with 6000 genes. Science 1996, 274(5287):546-563. 547.

34. Dean RA, Talbot NJ, Ebbole DJ, Farman ML, Mitchell TK, Orbach MJ, Thon M, Kulkarni R, Xu JR, Pan H, Read ND, Lee YH, Carbone I, Brown D, Oh YY, Donofrio N, Jeong JS, Soanes DM, Djonovic S, Kolomiets E, Rehmeyer C, Li W, Harding M, Kim S, Lebrun MH, Bohnert H, Coughlan S, Butler J, Calvo S, Ma LJ, Nicol R, et al: The genome sequence of the rice blast fungus Magnaporthe grisea. Nature 2005, 434(7036):980-986.

35. Labbe J, Murat C, Morin E, Tuskan GA, Le Tacon F, Martin F: Characterization of transposable elements in the ectomycorrhizal fungus Laccaria bicolor. Plos One 2012, 7(8):e40197.

36. Adomako D: Cocoa pod husk pectin. Phytochemistry 1972, 11(3):1145.

37. Gan P, Ikeda K, Irieda H, Narusaka M, O'Connell RJ, Narusaka Y, Takano Y, Kubo $Y$, Shirasu K: Comparative genomic and transcriptomic analyses reveal the hemibiotrophic stage shift of Colletotrichum fungi. New Phytol 2013, 197(4):1236-1249.

38. Garcia O, Macedo JAN, Tiburcio R, Zaparoli G, Rincones J, Bittencourt LMC, Ceita GO, Micheli F, Gesteira A, Mariano AC, Schiavinato MA, Medrano FJ, Meinhardt LW, Pereira GA, Cascardo JC: Characterization of necrosis and ethylene-inducing proteins (NEP) in the basidiomycete Moniliophthora perniciosa, the causal agent of witches' broom in Theobroma cacao. Mycol Res 2007, 111:443-455

39. Pemberton $\mathrm{CL}$, Salmond GP: The Nep1-like proteins-a growing family of microbial elicitors of plant necrosis. Mol Plant Pathol 2004 5(4):353-359.

40. Zaparoli G, Barsottini MR, de Oliveira JF, Dyszy F, Teixeira PJ, Barau JG, Garcia O, Costa-Filho AJ, Ambrosio AL, Pereira GA, Dias SM: The crystal structure of necrosis-and ethylene-inducing protein 2 from the causal agent of cacao's Witches' Broom disease reveals key elements for its activity. Biochemistry-Us 2011, 50(45):9901-9910.

41. Cabral A, Oome S, Sander N, Kufner I, Nurnberger T, Van den Ackerveken G: Nontoxic Nep1-like proteins of the downy mildew pathogen Hyaloperonospora arabidopsidis: repression of necrosis-inducing activity by a surface-exposed region. Mol Plant Microbe Interact 2012, 25(5):697-708.

42. Mosquera G, Giraldo MC, Khang CH, Coughlan S, Valent B: Interaction transcriptome analysis identifies magnaporthe oryzae BAS1-4 as Biotrophy-associated secreted proteins in rice blast disease. Plant Cell 2009, 21(4):1273-1290.

43. Paper JM, Scott-Craig JS, Adhikari ND, Cuomo CA, Walton JD: Comparative proteomics of extracellular proteins in vitro and in planta from the pathogenic fungus Fusarium graminearum. Proteomics 2007, 7(17):3171-3183.

44. van den Burg HA, Harrison SJ, Joosten MH, Vervoort J, de Wit PJ: Cladosporium fulvum Avr4 protects fungal cell walls against hydrolysis by plant chitinases accumulating during infection. Mol Plant Microbe Interact 2006, 19(12):1420-1430.

45. Roby D, Gadelle A, Toppan A: Chitin oligosaccharides as elicitors of chitinase activity in melon plants. Biochem Biophys Res Commun 1987, 143(3):885-892. 
46. Deising $H$, Siegrist J: Chitin deacetylase activity of the rust uromyces-viciaefabae is controlled by fungal morphogenesis. Fems Microbiol Lett 1995, 127(3):207-211.

47. Teixeira PJPL, Thomazella DPT, Vidal RO, Do Prado PFV, Reis O, Baroni RM, Franco SF, Mieczkowski P, Pereira GAG, Mondego JMC: The fungal pathogen moniliophthora perniciosa has genes similar to plant PR-1 that are highly expressed during its interaction with cacao. Plos One 2012, 7(9).

48. Riviere MP, Marais A, Ponchet M, Willats W, Galiana E: Silencing of acidic pathogenesis-related PR-1 genes increases extracellular beta-(1->3)glucanase activity at the onset of tobacco defence reactions. J Exp Bot 2008, 59(6):1225-1239.

49. Levy A, Guenoune-Gelbart D, Epel BL: beta-1,3-Glucanases: plasmodesmal gate keepers for intercellular communication. Plant Signal Behav 2007, 2(5):404-407.

50. Prados-Rosales RC, Roldan-Rodriguez R, Serena C, Lopez-Berges MS, Guarro J, Martinez-del-Pozo A, Di Pietro A: A PR-1-like protein of fusarium oxysporum functions in virulence on mammalian hosts. J Biol Chem 2012, 287(26):21970-21979.

51. Kershaw MJ, Talbot NJ: Hydrophobins and repellents: proteins with fundamental roles in fungal morphogenesis. Fungal Genet Biol 1998, 23(1):18-33.

52. Zelena K, Takenberg M, Lunkenbein S, Woche SK, Nimtz M, Berger RG: PfaH2: a novel hydrophobin from the ascomycete Paecilomyces farinosus. Biotechnol Appl Biochem 2013, 60(2):147-154.

53. Wosten HA: Hydrophobins: multipurpose proteins. Annu Rev Microbiol 2001, 55:625-646.

54. Bayry J, Aimanianda V, Guijarro Jl, Sunde M, Latge JP: Hydrophobins-unique fungal proteins. PLoS Pathog 2012, 8(5):e1002700.

55. De Oliveira AL, Gallo M, Pazzagli L, Benedetti CE, Cappugi G, Scala A, Pantera B, Spisni A, Pertinhez TA, Cicero DO: The structure of the elicitor cerato-platanin $(\mathrm{CP})$, the first member of the $\mathrm{CP}$ fungal protein family, reveals a double psi beta-barrel fold and carbohydrate binding. $J \mathrm{Bio} /$ Chem 2011, 286(20):17560-17568

56. Baccelli I, Comparini C, Bettini PP, Martellini F, Ruocco M, Pazzagli L, Bernardi R, Scala A: The expression of the cerato-platanin gene is related to hyphal growth and chlamydospores formation in Ceratocystis platani. Fems Microbiol Lett 2012, 327(2):155-163.

57. Zaparoli G, Cabrera OG, Medrano FJ, Tiburcio R, Lacerda G, Pereira GG Identification of a second family of genes in Moniliophthora perniciosa, the causal agent of witches' broom disease in cacao, encoding necrosisinducing proteins similar to cerato-platanins. Mycol Res 2009, 113:61-72.

58. Lombardi L, Faoro F, Luti S, Baccelli I, Martellini F, Bernardi R, Picciarelli P, Scala A, Pazzagli L: Differential timing of defense-related responses induced by cerato-platanin and cerato-populin, two non-catalytic fungal elicitors. Physiol Plant 2013, 149:408-421.

59. Yang Y, Zhang H, Li G, Li W, Wang X, Song F: Ectopic expression of MgSM1, a Cerato-platanin family protein from Magnaporthe grisea, confers broad-spectrum disease resistance in Arabidopsis. Plant Biotechnol J 2009, 7(8):763-777.

60. Bhadauria V, Banniza S, Vandenberg A, Selvaraj G, Wei Y: EST mining identifies proteins putatively secreted by the anthracnose pathogen Colletotrichum truncatum. Bmc Genomics 2011, 12:327.

61. Frischmann A, Neudl S, Gaderer R, Bonazza K, Zach S, Gruber S, Spadiut O, Friedbacher G, Grothe H, Seidl-Seiboth V: Self-assembly at air/water interfaces and carbohydrate binding properties of the small secreted protein EPL1 from the fungus trichoderma atroviride. J Biol Chem 2013, 288(6):4278-4287.

62. Jeong JS, Mitchell TK, Dean RA: The magnaporthe grisea snodprot1 homolog, MSP1, is required for virulence. Fems Microbiol Lett 2007, 273(2):157-165.

63. Peter M, Courty PE, Kohler A, Delaruelle C, Martin D, Tagu D, Frey-Klett P, Duplessis S, Chalot M, Podila G, Martin F: Analysis of expressed sequence tags from the ectomycorrhizal basidiomycetes Laccaria bicolor and Pisolithus microcarpus. New Phytol 2003, 159(1):117-129.

64. Cosgrove DJ: Loosening of plant cell walls by expansins. Nature 2000, 407(6802):321-326.

65. Quiroz-Castaneda RE, Martinez-Anaya C, Cuervo-Soto LI, Segovia L, Folch-Mallol JL: Loosenin, a novel protein with cellulose-disrupting activity from Bjerkandera adusta. Microb Cell Fact 2011, 10:8.

66. Brotman $Y$, Briff E, Viterbo A, Chet I: Role of swollenin, an expansin-like protein from Trichoderma, in plant root colonization. Plant Physiol 2008, 147(2):779-789.
67. Yamada M, Sakuraba S, Shibata K, Taguchi G, Inatomi S, Okazaki M, Shimosaka $\mathrm{M}$ : Isolation and analysis of genes specifically expressed during fruiting body development in the basidiomycete Flammulina velutipes by fluorescence differential display. Fems Microbio/ Lett 2006, 254(1):165-172.

68. Rincones J, Scarpari LM, Carazzolle MF, Mondego JMC, Formighieri EF, Barau JG, Costa GGL, Carraro DM, Brentani HP, Vilas-Boas LA, de Oliveira BV, Sabha M, Dias R, Cascardo JM, Azevedo RA, Meinhardt LW, Pereira GA: Differential gene expression between the biotrophic-like and saprotrophic mycelia of the witches' broom pathogen Moniliophthora perniciosa. Mol Plant Microbe In 2008, 21(7):891-908.

69. Zerbino DR, Birney E: Velvet: algorithms for de novo short read assembly using de Bruijn graphs. Genome Res 2008, 18(5):821-829.

70. Sommer DD, Delcher AL, Salzberg SL, Pop M: Minimus: a fast, lightweight genome assembler. BMC Bioinforma 2007, 8:64.

71. Ter-Hovhannisyan V, Lomsadze A, Chernoff YO, Borodovsky M: Gene prediction in novel fungal genomes using an ab initio algorithm with unsupervised training. Genome Res 2008, 18(12):1979-1990.

72. Stanke M, Keller O, Gunduz I, Hayes A, Waack S, Morgenstern B: AUGUSTUS: ab initio prediction of alternative transcripts. Nucleic Acids Res 2006, 34(Web Server issue):W435-W439.

73. Stanke M, Tzvetkova A, Morgenstern B: AUGUSTUS at EGASP: using EST, protein and genomic alignments for improved gene prediction in the human genome. Genome Biol 2006, 7(Suppl 1):S11 11-18.

74. Slater GS, Birney E: Automated generation of heuristics for biological sequence comparison. BMC Bioinforma 2005, 6:31.

75. Borodovsky M, Lomsadze A, Ivanov N, Mills R: Eukaryotic gene prediction using GeneMark.hmm. Curr Protoc Bioinformatics 2003, Chapter 4:Unit4 6

76. Haas BJ, Salzberg SL, Zhu W, Pertea M, Allen JE, Orvis J, White O, Buell CR, Wortman JR: Automated eukaryotic gene structure annotation using EVidenceModeler and the program to assemble spliced alignments. Genome Biol 2008, 9(1):R7.

77. Koski LB, Gray MW, Lang BF, Burger G: AutoFACT: an automatic functional annotation and classification tool. BMC Bioinforma 2005, 6:151.

78. Suzek BE, Huang H, McGarvey P, Mazumder R, Wu CH: UniRef: comprehensive and non-redundant UniProt reference clusters. Bioinformatics 2007, 23(10):1282-1288.

79. Bateman A, Birney E, Cerruti L, Durbin R, Etwiller L, Eddy SR, Griffiths-Jones S, Howe KL, Marshall M, Sonnhammer EL: The Pfam protein families database. Nucleic Acids Res 2002, 30(1):276-280.

80. Kanehisa M, Goto S: KEGG: kyoto encyclopedia of genes and genomes. Nucleic Acids Res 2000, 28(1):27-30.

81. Conesa A, Gotz S, Garcia-Gomez JM, Terol J, Talon M, Robles M: Blast2GO: a universal tool for annotation, visualization and analysis in functional genomics research. Bioinformatics 2005, 21(18):3674-3676.

82. McCarthy EM, MCDonald JF: LTR_STRUC: a novel search and identification program for LTR retrotransposons. Bioinformatics 2003, 19(3):362-367.

83. Jurka J, Kapitonov W, Pavlicek A, Klonowski P, Kohany O, Walichiewicz J: Repbase update, a database of eukaryotic repetitive elements. Cytogenet Genome Res 2005, 110(1-4):462-467.

84. Bailey B, Bae H, Strem M, Samuels G, Evans H, Thomas S, Holmes K: Molecular responses resulting from the endophytic association between Trichoderma species and cocoa (Theobroma cacao). Phytopathology 2005, 95(6):S5-S5.

85. Langmead B, Trapnell C, Pop M, Salzberg SL: Ultrafast and memoryefficient alignment of short DNA sequences to the human genome. Genome Biol 2009, 10(3):R25.

86. Anders S, Huber W: Differential expression analysis for sequence count data. Genome Biol 2010, 11(10):R106.

87. Livak KJ, Schmittgen TD: Analysis of relative gene expression data using real-time quantitative PCR and the 2(-Delta Delta $C(T)$ ) method. Methods 2001, 25(4):402-408.

88. Schmittgen TD, Livak KJ: Analyzing real-time PCR data by the comparative C(T) method. Nat Protoc 2008, 3(6):1101-1108

89. Pfaffl MW: A new mathematical model for relative quantification in real-time RT-PCR. Nucleic Acids Res 2001, 29(9):e45.

90. Petersen TN, Brunak S, Von Heijne G, Nielsen H: SignalP 4.0: discriminating signal peptides from transmembrane regions. Nat Methods 2011, 8(10):785-786.

91. Krogh A, Larsson B, Von Heijne G, Sonnhammer EL: Predicting transmembrane protein topology with a hidden Markov model: application to complete genomes. J Mol Biol 2001, 305(3):567-580. 
92. Sonnhammer EL, Von Heijne G, Krogh A: A hidden Markov model for predicting transmembrane helices in protein sequences. Proc Int Conf Intell Syst Mol Biol 1998, 6:175-182.

93. Frieman MB, Cormack BP: Multiple sequence signals determine the distribution of glycosylphosphatidylinositol proteins between the plasma membrane and cell wall in Saccharomyces cerevisiae. Microbiology 2004, 150(Pt 10):3105-3114.

94. Frieman MB, Cormack BP: The omega-site sequence of glycosylphosphatidy linositol-anchored proteins in Saccharomyces cerevisiae can determine distribution between the membrane and the cell wall. Mol Microbiol 2003, 50(3):883-896.

95. Poisson G, Chauve C, Chen X, Bergeron A: FragAnchor: a large-scale predictor of glycosylphosphatidylinositol anchors in eukaryote protein sequences by qualitative scoring. Genomics Proteomics Bioinformatics 2007, 5(2):121-130.

96. Kurtz S, Phillippy A, Delcher AL, Smoot M, Shumway M, Antonescu C, Salzberg SL: Versatile and open software for comparing large genomes. Genome Biol 2004, 5(2):R12.

97. Delcher AL, Phillippy A, Carlton J, Salzberg SL: Fast algorithms for large-scale genome alignment and comparison. Nucleic Acids Res 2002, 30(11):2478-2483.

doi:10.1186/1471-2164-15-164

Cite this article as: Meinhardt et al:: Genome and secretome analysis of the hemibiotrophic fungal pathogen, Moniliophthora roreri, which causes frosty pod rot disease of cacao: mechanisms of the biotrophic and necrotrophic phases. BMC Genomics 2014 15:164.

\section{Submit your next manuscript to BioMed Central and take full advantage of:}

- Convenient online submission

- Thorough peer review

- No space constraints or color figure charges

- Immediate publication on acceptance

- Inclusion in PubMed, CAS, Scopus and Google Scholar

- Research which is freely available for redistribution 